\title{
Exercise as Medicine-Evidence for Prescribing Exercise for the National Health Priority Areas: An Umbrella Review
}

\author{
Philippa J Inge ${ }^{1}$, Nirmala KP Perera ${ }^{2}$, John W Orchard $^{3}$, Leigh Golding ${ }^{4}$
}

\begin{abstract}
Objective: To describe the relationship between exercise and Australia's nine national health priority areas (NHPAs), which are arthritis and musculoskeletal conditions, asthma, cancer control, cardiovascular health, dementia, diabetes mellitus, injury prevention and control, mental health conditions, and obesity.

Materials and methods: CINAHL, Cochrane Database of Systematic Reviews, PubMed, and SPORTDiscus were searched from 2007 to 2017, inclusive. Included were systematic reviews and meta-analyses reporting the effect of exercise on development, management, and treatment of Australia's NHPAs.

Results: A total of 74 studies were fulfilling the inclusion criteria. Moderate exercise effectively treats and manages symptoms of osteoarthritis. Exercise improves maximal oxygen uptake in patients with asthma, prevents breast cancer, and reduces hospital admissions for patients with heart failure. Exercise significantly reduces the risk of type II diabetes mellitus and assists weight control. Exercise reduces the risk of vascular dementia, delays cognitive decline, and is effective in falls prevention. Exercise reduces symptoms of anxiety and is an effective treatment for people with depression.

Conclusion: Exercise had a positive/beneficial effect in all nine NHPAs. However, it doesn't have universal beneficial effect for every subdisease. From a clinical perspective, prescription of exercise to assist in the management and/or prevention of all of the nine NHPAs should be encouraged. Implications for public health: Exercise has a critical role in the national public health strategy for the prevention and treatment of diseases related to inactivity.

Keywords: Exercise, National health priority areas, Physical activity, Review.

Journal of Postgraduate Medicine, Education and Research (2020): 10.5005/.jp-journals-10028-1381
\end{abstract}

\section{INTRODUCTION}

Australia's Commonwealth, state, and territory governments established the National Health Priority Areas (NHPAs) initiative in 1996 in response to the World Health Organizations global strategy Health for all by the year 2000. Arthritis and musculoskeletal conditions, asthma, cancer control, cardiovascular health, dementia, diabetes mellitus, injury prevention and control, mental health, and obesity are the nine NHPAs and were chosen due to their significant contributions to the burden of disease in Australia. ${ }^{1}$ These health priority areas are similar to those in many other Western countries and represent both the major causes of death and chronic morbidity in many nations.

It is widely recognized that regular physical activity can prolong life, reduce the risk of cardiovascular disease, stroke, diabetes, cancer, osteoporosis, and improve mental health. ${ }^{2}$ There is strong evidence that a higher risk of mortality is associated with physical inactivity and sedentary behavior. ${ }^{3,4}$ For example, inactivity is attributable to $6 \%$ of coronary heart disease (CHD), $7 \%$ of type II diabetes mellitus (T2DM), $10 \%$ of breast cancer, and $10 \%$ of colon cancer globally. ${ }^{2}$ Accordingly, the Australian government has recognized that exercise has a critical role to play in Australia's national public health strategy for prevention of diseases related to inactivity.

However, activity levels among the Australian population remain low and according to the 2014-15 national health survey (NHS), only $55 \%$ of adults meet the recommended physical activity guidelines. ${ }^{4}$ The lack of sufficient physical activity in Australia is again echoed by a similar problem being noted in the majority of Western nations.

\begin{abstract}
${ }^{1,4}$ Australasian College of Sport and Exercise Physicians, Melbourne, Australia

${ }^{2}$ Unit of Physiotherapy, Department of Health, Medicine and Caring Sciences (HMV), Linköping University, Linköping, Sweden; University of Canberra Research Institute for Sport and Exercise, Canberra, Australia

${ }^{3}$ School of Public Health, University of Sydney, Australia

Corresponding Author: Philippa J Inge, Australasian College of Sport and Exercise Physicians, Melbourne, Australia, Phone: +61 421823626, e-mail: philippa.inge@gmail.com

How to cite this article: Inge PJ, Perera NKP, Orchard JW, et al. Exercise as Medicine-Evidence for Prescribing Exercise for the National Health Priority Areas: An Umbrella Review. J Postgrad Med Edu Res 2020;54(4):178-205.
\end{abstract}

Source of support: Nil

Conflict of interest: None

Currently, no reviews are available to explore the effect of exercise on Australia's nine NHPAs. The aim of this umbrella review is to examine the empirically published literature and describe the relationship between exercise and Australia's nine NHPAs.

\section{Materials and Methods}

An a priori study protocol was developed according to the Preferred Reporting Items for Systematic Reviews and Metaanalysis (PRISMA) guidelines ${ }^{5,6}$ and the Joanna Briggs Institute $(\mathrm{J} B \mathrm{I})$ reviewers manual-methodology for JBI umbrella 
reviews. ${ }^{6}$ The study protocol was registered on the PROSPERO International prospective register for systematic reviews (http://www.crd.york.ac.uk/PROSPERO/; registration number 42017073364).

Inclusion/exclusion criteria were developed ${ }^{7}$ (Appendix A) and four databases (CINAHL, Cochrane Database of Systematic Reviews, PubMed, and SPORTDiscus) were systematically searched from January 2007 to July 2017 inclusive, using criteria illustrated in Appendix B. Systematic reviews and meta-analyses published in a peer-reviewed journal reporting exercise and one or more of the nine NHPAs were included and the titles and abstracts were independently screened by the lead author against the criteria (Appendix A) and checked by a second author (NKPP). Relevant fulltext articles were then screened by the lead author. A publication was excluded from the review if it failed a single criterion and the first "no" response to any item on Appendix A was the primary reason for exclusion. When there were two or more studies available for the same topic including a Cochrane review, then the Cochrane review was selected to include in the analysis. This was because Cochrane reviewers are internationally recognized as the highest standard in evidence-based health care resources. If multiple reviews were available for the same topic and there was absence of a Cochrane review, then the review with the highest AMSTAR rating was selected.

Methodological quality of the included papers was assessed independently using the Assessing the Methodological Quality of Systematic Reviews (AMSTAR) tool ${ }^{8}$ by two reviewers (PI, NKPP). When there was a lack of consensus, the consensus was reached via discussion. Agreement between reviewers was determined by Kappa statistic. The lead author extracted the following key variables from the reviews: authors, year of publication, review summary, findings related to the effect of exercise on disease development, treatment, mortality, and secondary clinical outcomes such as quality of life (QOL).

\section{Results}

Of the 3,205 records identified in the initial keyword search, 74 reviews fulfilled the inclusion criteria and were included in the synthesis (Fig. 1).

A comprehensive collation of the 74 reviews including significant findings related to the effect of exercise on disease development, treatment, mortality, and secondary clinical outcomes such as QOL for each of the nine NHPAs is summarized Table 1 and elaborated in Appendix C. There were 11 reviews on arthritis and other musculoskeletal conditions, ${ }^{9-19} 6$ reviews on asthma, ${ }^{20-25} 13$ reviews on cancer, ${ }^{26-38} 7$ reviews on cardiovascular disease, ${ }^{39-45} 10$ reviews on dementia, ${ }^{46-55} 5$ reviews on diabetes, ${ }^{56-60} 6$ reviews on injury prevention and control, ${ }^{61-66} 11$ reviews on mental health, ${ }^{67-77}$ and 5 reviews in obesity. ${ }^{78-82}$

\section{Arthritis and Other Musculoskeletal Conditions}

Of the 11 reviews examining effects of exercise on arthritis and other musculoskeletal conditions, ${ }^{9-19} 4$ were on osteoarthritis $(\mathrm{OA}){ }^{10,13,14,19}, 3$ on rheumatoid arthritis, ${ }^{9,11,16} 3$ on lower back pain, ${ }^{12,18}$ and 2 on osteoporosis. ${ }^{15,17}$ There were six Cochrane reviews. ${ }^{10,12-16}$ There is high-quality evidence confirming that moderate exercise can be effectively used to treat and manage symptoms of $O A$ such as pain and functioning with moderate improvements in disability and QOL. ${ }^{10,13,14,19}$ A 2015 Cochrane review demonstrated compatible effects of exercise to nonsteroidal anti-inflammatory

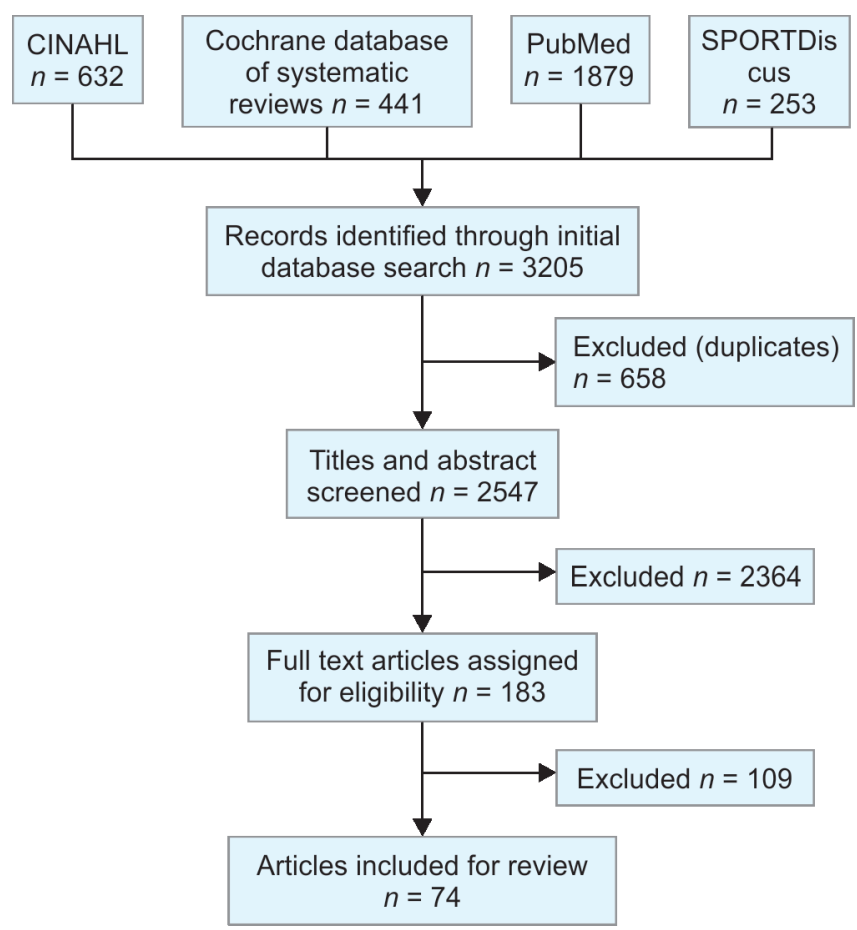

Fig. 1: PRISMA flowchart showing methodology for study inclusion

medications in the management of pain in knee OA..$^{13}$ In relation to rheumatoid arthritis, moderate-quality evidence supports exercise in improving aerobic capacity, muscle strength, and self-reported functional ability. ${ }^{11,16}$

Weight-bearing-based physical activity increases bone strength in children; however, there is insufficient evidence to support this in men and premenopausal women. ${ }^{17}$ In postmenopausal women, the most effective type of exercise on bone strength appears to be non-weight-bearing resistance activity with a relatively small but statistically significant effect when compared with control groups ${ }^{15}$ (Tables 1, 2 and Appendix C).

\section{Asthma}

Of the six reviews examining the effects of exercise on asthma, ${ }^{20-25}$ three focused on children. ${ }^{20,22,25}$ Three were Cochrane reviews. ${ }^{20,21,24}$ High-quality evidence demonstrated marked improvement in maximal oxygen uptake and QOL in children and adults with asthma but does not appear to improve pulmonary function. . $1,23,25^{2}$ The type of exercise was not specifically determined; however, all studies focused on aerobic-based activity. Swimming is particularly beneficial for children and adolescents with asthma ${ }^{20}$; however, no difference was found between water- and land-based training in adults (Tables 1, 2 and Appendix C).

\section{Cancer Control}

There were 13 reviews examining the effects of exercise on various forms of cancer. ${ }^{26-38}$ All forms of cancer were included in five studies ${ }^{29,31,33,36,38}$ and the remaining focused on breast, $27,32,37$ colorectal, ${ }^{30}$ lung, ${ }^{34}$, and prostate ${ }^{26,28,35}$ cancer. There were three Cochrane reviews. ${ }^{31,32,36}$ Evidence demonstrates an inverse relationship between physical activity and postmenopausal breast cancer with risk reductions ranging from 20 to $80 \%{ }^{37}$ Improvements in QOL, mood, fatigue, exercise capacity, and tolerance to treatment were found with all forms of cancer ${ }^{26-29,33-36}$ (Tables 1, 2 and Appendix C). 
Table 1: Systematic review summary of the effect of exercise on preventing and treating the nine priorities areas

\begin{tabular}{|c|c|c|c|}
\hline $\begin{array}{l}\text { National health priority } \\
\text { area }\end{array}$ & $\begin{array}{l}\text { Effect of exercise on disease } \\
\text { development }\end{array}$ & Effect of exercise on treatment & $\begin{array}{l}\text { Effect of exercise on secondary clinical } \\
\text { outcomes }\end{array}$ \\
\hline \multirow{3}{*}{$\begin{array}{l}\text { Arthritis and } \\
\text { musculoskeletal condi- } \\
\text { tions }\end{array}$} & \multirow[t]{3}{*}{-} & $\begin{array}{l}\text { Moderate exercise can be used to treat } \\
\text { and manage OA symptoms. }{ }^{10,13,14,19}\end{array}$ & $\begin{array}{l}\text { Improves pain, functional ability, and } \\
\text { QOL in patients with OA. }{ }^{0,13,14,19}\end{array}$ \\
\hline & & \multirow[t]{2}{*}{ 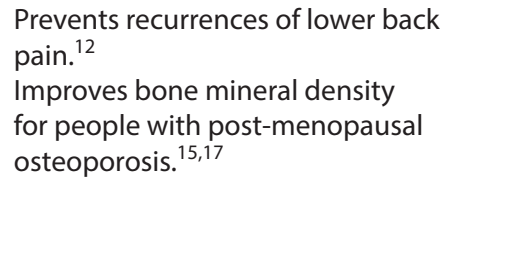 } & $\begin{array}{l}\text { Aerobic and resistance training } \\
\text { programs consistently improve aero- } \\
\text { bic capacity, muscle strength, and } \\
\text { QOL in patients with rheumatoid } \\
\text { arthritis. }{ }^{9,11}\end{array}$ \\
\hline & & & $\begin{array}{l}\text { Exercise needs to be tailored to } \\
\text { individual needs. }^{11}\end{array}$ \\
\hline \multirow[t]{2}{*}{ Asthma } & \multirow[t]{2}{*}{-} & $\begin{array}{l}\text { Improves maximal oxygen uptake in } \\
\text { children and adults but does not have } \\
\text { any effect on pulmonary function. }{ }^{21,22,25}\end{array}$ & $\begin{array}{l}\text { Positive effect on cardiorespiratory } \\
\text { fitness and improves QOL for adults } \\
\text { and children with asthma. }{ }^{21,22,25}\end{array}$ \\
\hline & & $\begin{array}{l}\text { Swimming is particularly beneficial for } \\
\text { children and adolescents with asthma. }{ }^{20}\end{array}$ & $\begin{array}{l}\text { Improves exercise-induced broncho- } \\
\text { constriction in children. }{ }^{21,22,25}\end{array}$ \\
\hline \multirow[t]{2}{*}{ Cancer } & $\begin{array}{l}\text { Prevention of breast cancer with } \\
\text { a risk reduction of } 20-80 \% .^{37}\end{array}$ & \multirow[t]{2}{*}{-} & $\begin{array}{l}\text { All studies except one }{ }^{32} \text { reported } \\
\text { improved QOL. }\end{array}$ \\
\hline & $\begin{array}{l}\text { Lack of evidence to support } \\
\text { exercise in the management of } \\
\text { colorectal cancer. }^{30}\end{array}$ & & $\begin{array}{l}\text { Improved symptoms including fa- } \\
\text { tigue, exercise capacity, and physical } \\
\text { functioning. }{ }^{29-31,33,36}\end{array}$ \\
\hline \multirow[t]{2}{*}{ Cardiovascular health } & \multirow[t]{2}{*}{-} & $\begin{array}{l}\text { Reduces risk of hospital admissions in } \\
\mathrm{CHD}^{40} \text { and heart failure. }{ }^{41,42,45}\end{array}$ & $\begin{array}{l}\text { Improves quality of life (QOL) in } \\
\text { heart failure. }{ }^{39,41,42,45}\end{array}$ \\
\hline & & $\begin{array}{l}\text { Cardiorespiratory training reduces } \\
\text { disability during or after usual stroke } \\
\text { care. }^{44}\end{array}$ & $\begin{array}{l}\text { No evidence to suggest exercise } \\
\text { rehabilitation causes harm. }{ }^{41,42,45} \\
\text { No effect on cause mortality in pa- } \\
\text { tients with heart failure. }{ }^{41,42,45}\end{array}$ \\
\hline \multirow[t]{2}{*}{ Dementia } & \multirow[t]{2}{*}{$\begin{array}{l}\text { Reduces the risk of vascular } \\
\text { dementia. }{ }^{46}\end{array}$} & \multirow{2}{*}{$\begin{array}{l}\text { Conflicting evidence as to whether } \\
\text { exercise positively influences cogni- } \\
\text { tive function in those with all types of } \\
\text { dementia. }{ }^{49,52}\end{array}$} & $\begin{array}{l}\text { Evidence supporting exercise to } \\
\text { improve the performance of } \\
\text { ADL's. }^{48,52}\end{array}$ \\
\hline & & & Improves physical functioning. ${ }^{50,52}$ \\
\hline \multirow[t]{2}{*}{ Diabetes mellitus } & $\begin{array}{l}\text { Prevents development of } \\
\text { T2DM. } .^{57} \text { Increased risk reduc- } \\
\text { tion when combined with } \\
\text { dietary interventions. }{ }^{60}\end{array}$ & \multirow[t]{2}{*}{$\begin{array}{l}\text { Reduces the incidence of disease pro- } \\
\text { gression from pre-diabetes to T2DM. }\end{array}$} & \multirow[t]{2}{*}{$\begin{array}{l}\text { When combined with dietary modifi- } \\
\text { cations, exercise has favorable effects } \\
\text { on BMI control. }{ }^{60}\end{array}$} \\
\hline & $\begin{array}{l}\text { Insufficient evidence to suggest } \\
\text { exercise reduces the risk of } \\
\text { gestational diabetes. }{ }^{58,59}\end{array}$ & & \\
\hline \multirow[t]{2}{*}{ Injury prevention } & $\begin{array}{l}\text { Reduces the falls risk and has a } \\
\text { significant role in falls preven- } \\
\text { tion and reducing the number } \\
\text { of injuries caused by falls }{ }^{61,62,66} \\
\text { and reduces the fear of } \\
\text { falling. }\end{array}$ & \multirow[t]{2}{*}{$\begin{array}{l}\text { Greatest improvement in falls preven- } \\
\text { tion is interventions that include exer- } \\
\text { cises that challenge balance. }{ }^{66}\end{array}$} & \multirow[t]{2}{*}{ - } \\
\hline & $\begin{array}{l}\text { Exercise-based injury preven- } \\
\text { tion programs reduce the risk of } \\
\text { acute and overuse injuries. }^{64,65}\end{array}$ & & \\
\hline Mental health & - & $\begin{array}{l}\text { Effective treatment for anxiety } 69,72,73,76,77 \\
\text { and depression. }{ }^{67,74} \text { Better results when } \\
\text { individually tailored. }{ }^{73}\end{array}$ & $\begin{array}{l}\text { Improves physical health, working } \\
\text { memory, attention, and social cogni- } \\
\text { tion of those with schizophrenia. }{ }^{71}\end{array}$ \\
\hline Obesity & - & $\begin{array}{l}\text { Exercise combined with diet and behav- } \\
\text { ior therapy is an effective weight loss } \\
\text { strategy in adults who are overweight } \\
\text { or obese. }\end{array}$ & $\begin{array}{l}\text { Improves BMI of children and } \\
\text { adolescents who are overweight or } \\
\text { obese. }^{78,80,81}\end{array}$ \\
\hline
\end{tabular}

$\mathrm{OA}$, osteoarthritis; $\mathrm{QOL}$, quality of life; $\mathrm{ADL}$, activities of daily living; T2DM, type II diabetes mellitus; $\mathrm{CHD}$, coronary heart disease; $\mathrm{BMI}$, body mass index 
Table 2: Summary of positive effects of exercise in general and postulated negative effects of subtypes of exercise

\begin{tabular}{|c|c|c|}
\hline $\begin{array}{l}\text { National health } \\
\text { priority area }\end{array}$ & $\begin{array}{l}\text { Positive effects of exercise (as revealed by } \\
\text { this umbrella review) }\end{array}$ & $\begin{array}{l}\text { Possible negative effects of any sub- } \\
\text { form of exercise (dose or type) }\end{array}$ \\
\hline $\begin{array}{l}\text { Arthritis and } \\
\text { musculoskel- } \\
\text { etal conditions }\end{array}$ & $\begin{array}{l}\text { Moderate exercise can be used to treat } \\
\text { and manage OA symptoms }{ }^{10,13,14,19} \text { and } \\
\text { lower back pain. }{ }^{12} \\
\text { Weight-bearing exercise improves bone } \\
\text { density in children and post-menopausal } \\
\text { women. }{ }^{17,18}\end{array}$ & $\begin{array}{l}\text { Possible "U"-shaped curve between } \\
\text { musculoskeletal conditions and ex- } \\
\text { ercise intensity; for example, higher } \\
\text { rates of OA seen in elite/extreme } \\
\text { sports competitors. }{ }^{83-85}\end{array}$ \\
\hline
\end{tabular}

Asthma

Improves QOL, exercise capacity, and maximal.

Swimming is particularly beneficial for children and adolescents with asthma. ${ }^{20}$

Cancer

Improves symptom control, fatigue, mood, and exercise tolerance during treatment.

Prevention of some cancers, particularly breast cancer, with a risk reduction of $20--80 \% .^{37}$

Cardiovascular Exercise reduces risk of hospital admishealth sions in $\mathrm{CHD}^{40}$ and heart failure. ${ }^{41,42,45}$ Improves blood pressure and cholesterol control.

Dementia

Exercise reduces the risk of vascular dementia. ${ }^{46}$

Improves ADL and functional performance.

Diabetes mel- Exercise prevents the development of litus

Injury prevention T2DM. ${ }^{57}$ Risk reduction is most effective when combined with dietary interventions. ${ }^{60}$

Exercise incorporating balance reduces falls risk and therefore has a significant role in falls prevention and reducing the number of injuries caused by falls $s^{61,62,66}$ and reduces the fear of falling in elderly. ${ }^{63}$

Exercise-based injury prevention programs reduce the risk of sporting injuries. $^{64,65}$

Mental health Effective treatment for anxiety ${ }^{69,72,73,76,77}$ and depression. ${ }^{67,74}$

Effective in reducing depressive episodes.

Obesity

Exercise combined with diet and behavior therapy is an effective weight loss strategy in adults ${ }^{82}$ and children and adolescents who are overweight or obese. $^{78,80,81}$

Summary for all nine NHPAs
Some types of exercise, particularly outdoor in cold weather, are thought to be a potential trigger of asthma attacks.

No negative effects of exercise known.

Theoretical reverse "IJ"' curve with some association postulated between extreme exercise and increased risk of arrhythmias and cardiomyopathy. ${ }^{86}$

Emerging evidence that recurrent concussions in collision sports (e.g., American football) may be associated with chronic traumatic encephalopathy. ${ }^{87}$

No known negative effects of exercise on T2DM.

Some sports, for example, those involving change of direction, are associated with injury (e.g., knee $A C L$ tears leading to surgery ${ }^{88}$ ).

Anecdotal evidence (only) suggests that exercise might be psychologically addictive in some individuals.

No known negative effects of exercise on obesity.

Highly competitive sport or extreme exercise, in particular, may have some negative effects on some NHPAs, of most concern in arthritis and musculoskeletal area.
Recommendations regarding exercise for this priority area

Moderate exercise can be highly recommended over sedentary behavior for generally preventing arthritis and musculoskeletal conditions.

More research is needed to identify a cutoff point for type and intensity of exercise between benefit and harm.

Exercise can be recommended for managing asthma, ensuring an appropriate asthma management plan is in place prior to the commencement of an exercise program

Exercise can be highly recommended for preventing and managing some cancers such as breast.

Exercise can be recommended for good cardiovascular health; further research is required to determine the exercise dose (if any), which becomes harmful for the heart.

Exercise can be recommended for preventing dementia (perhaps with the exception of collision sports)

Unequivocally, exercise can be highly recommended for prevention, management, and treatment of T2DM.

Exercise can be recommended over sedentary behavior for preventing falls. Sports (as a form of exercise) are associated with injury. Individual health benefitrisk profiles of various sports (generally health benefits vs. injury risk) need to be researched further.

Exercise can be recommended to maintain good mental health and psychological well-being.

Unequivocally, exercise can be highly recommended to prevent obesity.

Promotion of exercise (and exercise medicine) should be a priority for the health system. Further research needs to define dose-response cut-offs for the minority of situations where excessive exercise has some negative consequences.

$\mathrm{OA}$, osteoarthritis; $\mathrm{QOL}$, quality of life; $\mathrm{ADL}$, activities of daily living; $T 2 \mathrm{DM}$, type Il diabetes mellitus; $\mathrm{ACL}$, anterior cruciate ligament; $\mathrm{CHD}$, coronary heart disease 


\section{Cardiovascular Disease}

Of the seven reviews examining the effects of exercise on cardiovascular disease, ${ }^{39-45}$ there was one review each on atrial fibrillation, ${ }^{43} \mathrm{CHD}^{40}$ and stroke. ${ }^{44}$ Four reviews were on heart failure. ${ }^{39,41,42,45}$ There were five Cochrane reviews. ${ }^{40-43,45}$ Highquality evidence supports exercise in the management and prevention of many precursors to cardiovascular disease including hypertension, hypercholesterolemia, and diabetes. Exercise improves QOL in patients with heart failure $39,41,42,45$ and reduces hospital admissions; however, ${ }^{41,42,45}$ it has no significant effect on mortality. ${ }^{41,42,45}$ There was no evidence to suggest that exercise rehabilitation causes harm. ${ }^{41,42,45}$

Cardiorespiratory training reduces disability during or after usual stroke care through improved balance and walking tolerance. Due to a lack of studies, there is insufficient evidence to comment on the effect of exercise on mortality or cognition ${ }^{44}$ (Tables 1, 2 and Appendix C).

\section{Dementia}

Of the 10 reviews examining the effects of exercise on dementia, ${ }^{46-55}$ only 1 review focused on vascular dementia. ${ }^{46}$ There were two Cochrane reviews. ${ }^{48,55}$ Exercise reduces the risk of vascular dementia; ${ }^{46}$ however, it does not reduce the risk of Alzheimer's dementia. It improves global cognition, attention, and executive function in people with mild cognitive impairment (Tables 1, 2 and Appendix C).

\section{Diabetes}

Of the five reviews examining the relationship between exercise and diabetes, ${ }^{56-60}$ two reviews investigated gestational diabetes. ${ }^{58,59}$ There were three Cochrane reviews. ${ }^{58-60}$ There is evidence of an inverse relationship between physical activity and the risk of developing T2DM. ${ }^{57,60}$ Exercise combined with diet and behavioral interventions has favorable effects on weight and body mass index (BMI) control. ${ }^{60}$ There is no clear evidence that exercise reduces the risk of gestational diabetes ${ }^{59}$ (Tables 1, 2 and Appendix C).

\section{Injury Prevention and Control}

Four reviews examined the role of exercise in falls prevention, ${ }^{61-63,66}$ and two reviews examined exercise in sports injury prevention..$^{64,65}$ There was one Cochrane review. ${ }^{63}$ Exercise reduces risk of falls, injuries caused by falls, and reduces the fear of falling. ${ }^{61,62,65}$ Exercise-based injury prevention programs reduce the risk of acute and overuse sporting injuries ${ }^{64,65}$ (Tables 1, 2 and Appendix C).

\section{Mental Health}

Of the 11 reviews examining the role of mental health, ${ }^{67-77}$ there were 5 reviews on anxiety, ${ }^{69,72,73,76,77} 2$ on depression, ${ }^{67,74} 2$ on postnatal depression, ${ }^{68,75}$ and 2 reviews on schizophrenia. ${ }^{70,71}$ There were two Cochrane reviews. ${ }^{67,71}$ Exercise therapy was effective in reducing symptoms of anxiety. ${ }^{69,72,73,76,77}$ In the treatment of depression, ${ }^{67,74}$ it is moderately more effective than control interventions in reducing symptoms; however, effect size was small. When compared to psychological or pharmacological interventions, exercise appears to be no more effective; however, this conclusion is based on a few small trials ${ }^{67}$ (Tables 1, 2 and Appendix C).

\section{Obesity}

Of the five reviews examining the role of exercise in obesity, ${ }^{78-82}$ only one review was in adults. ${ }^{82}$ Exercise improves BMI of children and adolescents who are overweight or obese. ${ }^{78,80,81}$ Exercise needs to be combined with diet and behavior therapy to achieve significant weight loss in adults who are overweight or obese ${ }^{82}$ (Tables 1, 2 and Appendix C).

\section{Methodological Quality}

The AMSTAR ${ }^{8}$ methodological quality assessment results and the inter-rater agreement are presented in Appendix D. The inter-rater agreement was substantial $(k=0.872)$, with raters agreeing on 770 of 814 items (94\%). Consensus was reached on 50 items following discussions. A total of 14 studies $^{16,20,21,24,29,31,32,36,44,48,55,58,63,67}$ reached maximum quality and thus have a low risk of bias. The mean score was 7.8 .

\section{Discussion}

Overall, exercise had a positive effect (either in prevention or treatment) in all nine NHPAs. However, it does not have a universally beneficial effect for every subdisease of the NHPAs. The strength of this umbrella review is the synthesis of the effects of exercise in such a diverse range of health conditions, with a focus on Australia's National Health Priorities. The major and obvious limitation is that when considering such a diverse range of conditions, the analysis of and scrutiny given to the systematic reviews is necessarily rudimentary. Despite this limitation, we believe that there will be little controversy regarding our conclusions, as the consistency in systematic review conclusions was very high. That is, we did not encounter many instances of contradictory high-quality recent reviews of a priority area overall. It is beyond the depth of this umbrella review, but there would be heterogeneity when analyzing the myriad subconditions in each priority area.

While our search strategy was able to identify 74 review papers showing positive associations between exercise and a disease within a NHPA, to remain unbiased, it is important to highlight potential negative effects associated with exercise, particularly in excess. The term "exercise" in isolation appears to denote (moderate) exercise, for which we have uncovered almost universally positive effects. The aim of our paper was to examine the effects of exercise (in general) as opposed to competitive, elite, or professional sport; thus, these terms were not included in our inclusion/exclusion criteria.

For arthritis and musculoskeletal conditions, injury prevention and control, and cardiovascular conditions, in particular, the effect of exercise might be a nonlinear dose-response curve with negative effects seen at high exercise doses. By contrast, moderate doses of exercise have a protective effect on both cardiovascular and musculoskeletal health. Positive effects of exercise in relation to each of the nine NHPAs found in this umbrella review and any known or postulated negative associations with exercise (either in type or excessive dose) are summarized in Table 2, to allow summary findings to be used as a quick practical guide.

According to the $2015-16$ NHS, $15.3 \%$ of Australians live with arthritis ${ }^{4}$, and currently, there is no cure. We found that moderate exercise is effective in the treatment and management of symptoms such as pain, functioning, and QOL. ${ }^{10,13,14,19}$ Individually tailored exercise programs were more effective in management of OA. Overall, it is clear that moderate exercise prevents arthritis; however, prescription need to take into account possible side effects including injuries such as anterior cruciate ligament and meniscal injuries sustained by participating in some types of elite or extreme sports can lead to knee OA. ${ }^{83,84}$ A recent Australian study found that although a majority of sports injuries are of low severity, a significant proportion of community-level players (42\%) choose to self-treat or 
not to treat their injuries with many injuries relating to joints. This is concerning because poorly managed joint injuries can predispose people to the development of chronic health conditions such as OA. Primary healthcare providers have an important role in terms of education, treatment, and prevention of sports injuries.

The $2015-16$ NHS reported that $11.3 \%$ of Australians have hypertension, $5.2 \%$ have heart disease, $7.1 \%$ have high cholesterol, and $5.1 \%$ have diabetes (including $4.4 \%$ with T2DM). In addition, $63.4 \%$ adults and $27.4 \%$ children are overweight or obese. ${ }^{4}$ Exercise improves the QOL in patients with heart failure ${ }^{39,41,42,45}$ and reduces hospital admissions. ${ }^{39,41,42,45}$ There is an inverse relationship between exercise and reducing the risk of T2DM. ${ }^{57,60}$ Exercise improves glucose control in those with T2DM. ${ }^{56}$ It also induces significant weight loss in adults ${ }^{82}$ but need to be combined with a restrictive diet for adults who are overweight and obese with T2DM. ${ }^{57}$ In addition, exercise improves the BMI of overweight and obese children and adolescents ${ }^{78,80,81}$ and reduces risk factors for cardiovascular disease. These conditions are the main component of metabolic syndrome. Given that a significant proportion of Australians are affected by metabolic syndrome, the potential burden to individuals and the government in terms of cost of health care may be onerous. Primary healthcare providers such as general practitioners require an important knowledge base in terms of exercise prescription to provide positive outcomes, both financial and educational. It may also fall to primary care services to provide appropriate resources to educate the community to facilitate effective delivery of appropriated exercise programs.

There is a small subset of cardiovascular conditions (certain hypertrophic cardiomyopathies and arrhythmias such as arrhythmogenic right ventricular cardiomyopathy (AVRC) and atrial fibrillation ${ }^{40}$ ) where extreme exercise is now considered a possible risk factor for cardiovascular pathology. ${ }^{89}$ The cut-off for cardiovascular "harm" is controversial and not well established ${ }^{89}$ (Table 2). This should be differentiated from the paradox observed where exercising individuals overall have a much lower risk of sudden cardiac death than the general population, but if they do suffer a cardiac arrest, it is most likely to be during exercise. ${ }^{86}$ In both the musculoskeletal and cardiovascular diseases, the negative effects of a sedentary lifestyle are almost certainly greater than the negative effects of high-intensity exercise. The concept of a "U"-shaped curve has been previously cited (both musculoskeletal ${ }^{90}$ and cardiovascular ${ }^{91}$ ) to convey the concept that both inadequate and excessive exercise intensities may be harmful. The findings of our review suggest that the shape of a such graph is more likely to be an inverse "J." The negative effect of extreme exercise loads vs moderate may exist with respect to some NHPAs but these negative effects are probably overstated.

In 2015 , it was estimated that 342,800 people were living with dementia. It is Australia's second leading cause of deaths ${ }^{92}$ and with the ageing population (16\% of Australians over the age of 65 ) this is expected to grow. ${ }^{92}$ Physical activity prevents vascular dementia. ${ }^{46}$ It delays cognitive decline ${ }^{53}$ and improves global cognition, attention and executive function ${ }^{50}$, and physical functioning ${ }^{50,52,54}$ in those with dementia. Although there was overwhelming evidence that "exercise" in general was beneficial in dementia, it is important to be aware of the concerns of the association between some high-collision sports (such as boxing and American football) and a subtype of dementia known as chronic traumatic encephalopathy (CTE).
Falls were the leading external cause of hospitalizations in older Australians with approximately 96,000 cases in 2011-12, and the rate increases with increasing age. ${ }^{93}$ Exercise has a significant role in falls prevention and reduction of injury frequency. ${ }^{61,62,66}$ Most falls occur as a result of poor neuromuscular control, poor strength, and loss of balance. Interventions incorporating exercise that challenges balance have a great effect preventing falls. ${ }^{66}$ This information is useful to the healthcare providers in designing and implementing exercise programs for falls prevention.

Asthma affect $10.8 \%$ Australians, with the prevalence increasing by $1 \%$ since $2007-8 .{ }^{4}$ Exercise improves maximal oxygen uptake and significantly improves QOL in adults with asthma ${ }^{23}$ but does not appear to improve pulmonary function. ${ }^{21,23}$ There is a positive effect on cardiorespiratory fitness and exercise-induced bronchoconstriction in children ${ }^{25}$ with swimming being particularly beneficial as it increases the maximal lung capacity. ${ }^{20}$ With the increasing prevalence of asthma, it is important to incorporate exercise as part of the treatment regimen for improving QOL for asthma sufferers.

Anxiety affects $11.2 \%$ of Australians with $9.3 \%$ being affected by depression. ${ }^{4}$ Exercise was effective in reducing the symptoms of anxiety ${ }^{69,72,73,76}$ and treatment for people with depression. ${ }^{67,74}$ It should be noted that in certain instances it is as effective as psychological or pharmacological treatments. ${ }^{67}$ Given the prevalence of mental health conditions is increasing, it is important to be aware of the role of exercise as an effective treatment.

The overall benefits of exercise clearly outweigh the associated risks with the dangers of inactivity being a risk factor for many cancers, obesity, many cardiovascular conditions, dementia, mental health conditions, T2DM, and stroke. ${ }^{2}$ Inactivity is one of the major modifiable risk factors for chronic disease. However, only $55 \%$ of adults met the recommended physical activity guidelines with $30 \%$ Australians insufficiently active and $15 \%$ inactive. ${ }^{4}$ In the past, smoking was known as the single worst risk factor for predicting bad health at the individual level; however, in Australia, $15 \%$ of the population smoke; ${ }^{94}$ yet, $45 \%$ of the population are insufficiently active. This increases their risk for a myriad of chronic health conditions. Exercise has well and truly become the greatest population health challenge for Australia for the twenty-first century and healthcare professionals have the responsibility to promote exercise at every opportunity so as to improve the overal health of the population.

\section{Strengths and Limitations of this Umbrella Review}

This is the first comprehensive study to collate and analyze all published systematic reviews and meta-analyzes in peer-reviewed journals from January 2007 to July 2017, inclusive on the relationship of exercise on Australia's nine NHPAs. The strength of this umbrella review is the sensitive search strategy with 3,205 articles assessed, strong methodological rigor was maintained by using an a priori study protocol based on the PRISMA guidelines ${ }^{5}$, and risk of bias assessed using the AMSTAR tool. ${ }^{8}$ Both highly accepted tools were used to maintain methodological rigor. Methodological quality was assessed by two independent reviewers with the substantial inter-rater agreement. Included studies were of a high methodological quality. This umbrella review, therefore, provides a reliable overview of current data pertaining to exercise and the nine NHPAs. However, the results should be interpreted with caution due to other limitations, discussed below. 
The synthesis of evidence presented in this review is restricted by the reporting limitations that were presented in each included review. There was heterogeneity of findings when myriad subconditions considered for each NHPA. That is, for example, exercise is proven to be beneficial in preventing and treating individual cancers such as breast cancer, ${ }^{37}$ but it has not been universally shown to be protective or able to treat all subtypes of cancer. In addition, the definition of exercise used across the studies was different; thus, this review was unable to accurately compare findings.

\section{Conclusion}

From a clinical perspective, prescription of exercise to assist in the management and/or prevention of all of the nine NHPAs should be encouraged. For better results and improved compliance, exercise prescription should be enjoyable, individualized, and achievable with regular follow-up and support provided. There are possible negative effects of extreme-dose or highly competitive exercise, but these are generally overstated with the effects of sedentary behavior being of far greater net harm.

\section{Practical Implications for Public Health}

- Exercise has a critical role to play in Australia's national public health strategy in the prevention and treatment of disease.

- Exercise is effective to some extent in all of the nine NHPAs.

- About $45 \%$ of Australian population is insufficiently active; therefore, increased emphasis needs to be on encouraging physical activity in the general population.

- The Australian Activity Guidelines of "30 minutes of moderateintensity activity on most, if not all days" is safe to recommend.

\section{References}

1. Australian Institute of Health and Welfare (AU). National Health Priority areas 20132013 Available from: https://www.aihw.gov.au/ reports/health-care-quality-performance/national-health-priorityareas-first-report/related-material.

2. Lee IM, Shiroma EJ, Lobelo F, et al. Effect of physical inactivity on major non-communicable diseases worldwide: an analysis of burden of disease and life expectancy. Lancet 2012;380(9838):219-229. DOI: 10.1016/S0140-6736(12)61031-9.

3. National Preventative Health Task Force. Taking Preventative Action, a response to Australia: the healthiest country by 2020, the report of the National Preventative Taskforce. Canberra: Commonwealth of Australia; 2010.

4. Australian Bureau of Statistics. 4364.0.55.001-National Health Survey: First Results, 2014-15 Canberra Australian Bureau of Statistics; 2016.

5. Moher D, Liberati A, Tetzlaff J, et al. Preferred reporting items for systematic reviews and meta-analyses: the PRISMA statement. PLoS Med 2009;6(7):e1000097. DOI: 10.1371/journal.pmed.1000097.

6. JBI Reviewers manual 2014.

7. Moher D, Tricco A. Issues related to the conduct of systematic reviews: a focus on the nutrition field. Am J Clin Nutr 2008;88(5): 1191-1199.

8. Shea BJ, Grimshaw JM, Wells GA, et al. Development of AMSTAR: a measurement tool to assess the methodological quality of systematic reviews. BMC Med Res Methodol 2007;7:10. DOI: 10.1186/1471-22887-10.

9. Baillet A, Zeboulon N, Gossec L, et al. Efficacy of cardiorespiratory aerobic exercise in rheumatoid arthritis: meta-analysis of randomized controlled trials. Arthritis Care Res (Hoboken) 2010;62(7):984-992. DOI: 10.1002/acr.20146.

10. Bartels EM, Juhl CB, Christensen R, et al. Aquatic exercise for the treatment of knee and hip osteoarthritis. Cochrane Database Syst Rev 2016(3):CD005523. Available from: http://onlinelibrary.wiley.com/ doi/10.1002/14651858.CD005523.pub3/abstract http://onlinelibrary. wiley.com/store/10.1002/14651858.CD005523.pub3/asset/CD00552 $3 p d f ? v=1 \& t=j 5 h s 83 i d \& s=$ baece127ab0c88b0ab6778ff54531a90d 34 $596 \mathrm{e}$.

11. Cairns AP, McVeigh JG. A systematic review of the effects of dynamic exercise in rheumatoid arthritis. Rheumatol Int 2009;30(2):147-158. DOI: 10.1007/s00296-009-1090-5.

12. Choi BK, Verbeek JH, Tam WW-S, et al. Exercises for prevention of recurrences of low-back pain. Cochrane Database Syst Rev 2010(1):CD006555. Available from: http://onlinelibrary.wiley.com/ doi/10.1002/14651858.CD006555.pub2/abstract.

13. Fransen M, McConnell S, Harmer AR, et al. Exercise for osteoarthritis of the knee. Cochrane Database Syst Rev 2015(1):CD004376. Available from: http://onlinelibrary.wiley.com/doi/10.1002/14651858. CD004376.pub3/abstract http://onlinelibrary.wiley.com/ store/10.1002/14651858.CD004376.pub3/asset/CD004376.pdf?v=1 $\& t=j 5 h s t v 8 f \& s=1 a 078 c c b f a a b 65 a 881079 c 3296 f 2 c 2 c f 4 d e f 31 e 9$.

14. Fransen M, McConnell S, Hernandez-Molina G, et al. Exercise for osteoarthritis of the hip. Cochrane Database Syst Rev 2014(4):CD007912. Available from: http://onlinelibrary.wiley.com/ doi/10.1002/14651858.CD007912.pub2/abstract http://onlinelibrary. wiley.com/store/10.1002/14651858.CD007912.pub2/asset/CD007912. pdf? $v=1 \& t=j 5 h s u t 34 \& s=a d 6 e d 5 e d 6 c 1 e a 0005 a 1251 f a 273 e 857 d f 9 a 4$ 5 de9.

15. Howe TE, Shea B, Dawson LJ, et al. Exercise for preventing and treating osteoporosis in postmenopausal women. Cochrane Database Syst Rev 2011(7):Available from: http://onlinelibrary.wiley.com/ doi/10.1002/14651858.CD000333.pub2/abstract.

16. Hurkmans E, van der Giesen FJ, Vliet VTP, et al. Dynamic exercise programs (aerobic capacity and/or muscle strength training) in patients with rheumatoid arthritis. Cochrane Database Syst Rev 2009(4):CD006853. Available from: http://onlinelibrary.wiley.com/ doi/10.1002/14651858.CD006853.pub2/abstract.

17. Nikander $\mathrm{R}$, Sievanen $\mathrm{H}$, Heinonen $\mathrm{A}$, et al. Targeted exercise against osteoporosis: A systematic review and meta-analysis for optimising bone strength throughout life. BMC Med 2010;8:47. DOI: 10.1186/17417015-8-47.

18. Oesch $\mathrm{P}$, Kool J, Hagen KB, et al. Effectiveness of exercise on work disability in patients with non-acute non-specific low back pain: systematic review and meta-analysis of randomised controlled trials. J Rehabil Med 2010;42(3):193-205. DOI: 10.2340/16501977-0524.

19. Waller $B$, Ogonowska-Slodownik A, Vitor $M$, et al. Effect of therapeutic aquatic exercise on symptoms and function associated with lower limb osteoarthritis: systematic review with meta-analysis. Phys Ther 2014;94(10):1383-1395. DOI: 10.2522/ptj.20130417.

20. Beggs $S$, Foong YC, Le HCT, et al. Swimming training for asthma in children and adolescents aged 18 years and Under. Cochrane Database Syst Rev 2013(4):CD009607. Available from: http:// onlinelibrary.wiley.com/doi/10.1002/14651858.CD009607.pub2/ abstract http://onlinelibrary.wiley.com/store/10.1002/14651858. CD009607.pub2/asset/CD009607.pdf? v=1\&t=j5hw1a43\&s=89359d 5a373d9680e08a5f2e670f92efbc5d5cff.

21. Carson KV, Chandratilleke MG, Picot J, et al. Physical training for asthma. Cochrane Database Syst Rev 2013(9):CD001116. Available from: http:// onlinelibrary.wiley.com/doi/10.1002/14651858.CD001116.pub4/ abstract http://onlinelibrary.wiley.com/store/10.1002/14651858. CD001116.pub4/asset/CD001116.pdf? $v=1 \& t=j 5 h w 27 v n \& s=2 a c 6 e d$ 4ab577cb79f949800a94e440b21c326863.

22. Crosbie A. The effect of physical training in children with asthma on pulmonary function, aerobic capacity and health-related quality of life: a systematic review of randomized control trials. Pediatr Exerc Sci 2012;24(3):472-489. DOI: 10.1123/pes.24.3.472. 
23. Eichenberger PA, Diener SN, Kofmehl R, et al. Effects of exercise training on airway hyperreactivity in asthma: a systematic review and meta-analysis. Sports Med 2013;43(11):1157-1170. DOI: 10.1007/ s40279-013-0077-2.

24. Grande AJ, Silva V, Andriolo BN, et al. Water-based exercise for adults with asthma. Cochrane Database Syst Rev 2014(7):CD010456. Available from: http://onlinelibrary.wiley.com/doi/10.1002/14651858. CD010456.pub2/abstract http://onlinelibrary.wiley.com/ store/10.1002/14651858.CD010456.pub2/asset/CD010456.pdf?v=1 $\& t=j 5 h w 4 w v t \& s=e 10 e a 6 e 84 f c a 9 f e a 24 b 11 d b e 718$ ed39170bce089.

25. Wanrooij VH, Willeboordse $\mathrm{M}$, Dompeling E, et al. Exercise training in children with asthma: a systematic review. Br J Sports Med 2014;48(13):1024-1031. DOI: 10.1136/bjsports-2012-091347.

26. Baumann FT, Zopf EM, Bloch W. Clinical exercise interventions in prostate cancer patients: a systematic review of randomized controlled trials. Support Care Cancer 2012;20(2):221-233. DOI: 10.1007/s00520-011-1271-0.

27. Bicego $D$, Brown $K$, Ruddick M, et al. Effects of exercise on quality of life in women living with breast cancer: a systematic review. Breast J 2009;15(1):45-51. DOI: 10.1111/j.1524-4741.2008.00670.x.

28. Bourke L, Smith D, Steed L, et al. Exercise for men with prostate cancer: a systematic review and meta-analysis. Eur Urol 2016;69(4):693-703. DOI: 10.1016/j.eururo.2015.10.047.

29. Buffart LM, Kalter J, Sweegers MG, et al. Effects and moderators of exercise on quality of life and physical function in patients with cancer: an individual patient data meta-analysis of $34 \mathrm{RCTs}$. Cancer Treat Rev 2017;52:91-104. DOI: 10.1016/j.ctrv.2016.11.010.

30. Cramer $H$, Lauche $R$, Klose $P$, et al. A systematic review and metaanalysis of exercise interventions for colorectal cancer patients. Eur J Cancer Care (Engl) 2014;23(1):3-14. DOI: 10.1111/ecc.12093.

31. Cramp F, Byron-Daniel J. Exercise for the management of cancer-related fatigue in adults. Cochrane Database Syst Rev 2012(11):CD006145. Available from: http://onlinelibrary.wiley.com/ doi/10.1002/14651858.CD006145.pub3/abstract.

32. Furmaniak AC, Menig $M$, Markes $M H$. Exercise for women receiving adjuvant therapy for breast cancer. Cochrane Database Syst Rev 2016(9):CD005001. Available from: http://onlinelibrary.wiley.com/ doi/10.1002/14651858.CD005001.pub3/abstract.

33. Gerritsen JK, Vincent AJ. Exercise improves quality of life in patients with cancer: a systematic review and meta-analysis of randomised controlled trials. Br J Sports Med 2016;50(13):796-803. DOI: 10.1136/ bjsports-2015-094787.

34. Granger CL, McDonald CF, Berney S, et al. Exercise intervention to improve exercise capacity and health related quality of life for patients with non-small cell lung cancer: a systematic review. Lung Cancer 2011;72(2):139-153. DOI: 10.1016/j.lungcan.2011. 01.006 .

35. Keogh JW, MacLeod RD. Body composition, physical fitness, functional performance, quality of life, and fatigue benefits of exercise for prostate cancer patients: a systematic review. J Pain and Symptom Manage 2012;43(1):96-110. DOI: 10.1016/j.jpainsymman.2011. 03.006.

36. Mishra SI, Scherer RW, Geigle PM, et al. Exercise interventions on health-related quality of life for cancer survivors. Cochrane Database Syst Rev 2012(8):CD007566. Available from: http://onlinelibrary.wiley. com/doi/10.1002/14651858.CD007566.pub2/abstract.

37. Monninkhof EM, Elias SG, Vlems FA, et al. Physical activity and breast cancer: a systematic review. Epidemiology 2007;18(1):137-157. DOI: 10.1097/01.ede.0000251167.75581.98.

38. Winzer BM, Whiteman DC, Reeves MM, et al. Physical activity and cancer prevention: a systematic review of clinical trials. Cancer Causes Control 2011;22(6):811-826. DOI: 10.1007/s10552-011-9761-4.

39. Adsett JA, Mudge AM, Morris N, et al. Aquatic exercise training and stable heart failure: a systematic review and meta-analysis. Int J Cardiol 2015;186:22-28. DOI: 10.1016/j.ijcard.2015.03.095.

40. Anderson L, Thompson DR, Oldridge N, et al. Exercise-based cardiac rehabilitation for coronary heart disease. Cochrane Database Syst Rev 2016(1):CD001800. DOI: 10.1002/14651858.CD001800.pub3.
41. Davies EJ, Moxham T, Rees K, et al. Exercise training for systolic heart failure: cochrane systematic review and meta-analysis. Eur J Heart Fail 2010;12(7):706-715. DOI: 10.1093/eurjhf/hfq056.

42. Lewinter C, Doherty P, Gale CP, et al. Exercise-based cardiac rehabilitation in patients with heart failure: a meta-analysis of randomised controlled trials between 1999 and 2013. Eur J Prev Cardiol 2015;22(12):1504-1512. DOI: 10.1177/2047487314559853.

43. Risom SS, Zwisler A-D, Johansen PP, et al. Exercise-based cardiac rehabilitation for adults with atrial fibrillation. Cochrane Database Syst Rev 2017(2):CD011197. Available from: http://onlinelibrary.wiley. com/doi/10.1002/14651858.CD011197.pub2/abstract.

44. Saunders $D H$, Sanderson $M$, Hayes $S$, et al. Physical fitness training for stroke patients. Cochrane Database Syst Rev 2016;3:CD003316. DOI: 10.1002/14651858.CD003316.pub6.

45. Taylor RS, Sagar VA, Davies EJ, et al. Exercise-based rehabilitation for heart failure. Cochrane Database Syst Rev 2014(4):CD003331. Available from: http://onlinelibrary.wiley.com/doi/10.1002/14651858. CD003331.pub4/abstract http://onlinelibrary.wiley.com/ store/10.1002/14651858.CD003331.pub4/asset/CD003331.pdf?v=1 $\& t=j 5 i 0 t 2 g 8 \& s=5846669 d 3 f 9 a 89825 b 980 d c 3 b 04811 d c f 177 b e a 9$.

46. Aarsland D, Sardahaee FS, Anderssen S, et al. Is physical activity a potential preventive factor for vascular dementia? A systematic review. Aging Ment Health 2010;14(4):386-395. DOI: 10.1080/13607860903586136.

47. Barreto Pde S, Demougeot L, Pillard F, et al. Exercise training for managing behavioral and psychological symptoms in people with dementia: a systematic review and meta-analysis. Ageing Res Rev 2015;24(Pt B):274-285. DOI: 10.1016/j.arr.2015.09.001.

48. Forbes D, Forbes SC, Blake CM, et al. Exercise programs for people with dementia. Cochrane Database Syst Rev 2015(4):CD00648. Available from: http://onlinelibrary.wiley.com/doi/10.1002/14651858. CD006489.pub4/abstract http://onlinelibrary.wiley.com/ store/10.1002/14651858.CD006489.pub4/asset/CD006489.pdf?v=1

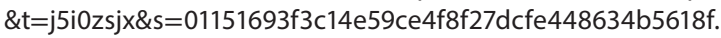

49. Groot C, Hooghiemstra AM, Raijmakers PG, et al. The effect of physical activity on cognitive function in patients with dementia: a metaanalysis of randomized control trials. Ageing Res Rev 2016;25:13-23. DOI: 10.1016/j.arr.2015.11.005.

50. Laver K, Dyer S, Whitehead C, et al. Interventions to delay functional decline in people with dementia: a systematic review of systematic reviews. BMJ Open 2016;6(4):e010767. DOI: 10.1136/bmjopen-2015010767.

51. Law LL, Barnett F, Yau MK, et al. Effects of combined cognitive and exercise interventions on cognition in older adults with and without cognitive impairment: a systematic review. Ageing Res Rev 2014;15:61-75. DOI: 10.1016/j.arr.2014.02.008.

52. Littbrand $H$, Stenvall M, Rosendahl E. Applicability and effects of physical exercise on physical and cognitive functions and activities of daily living among people with dementia: a systematic review. Am J Phys Med Rehabil 2011;90(6):495-518. DOI: 10.1097/ PHM.0b013e318214de26.

53. Ohman H, Savikko N, Strandberg TE, et al. Effect of physical exercise on cognitive performance in older adults with mild cognitive impairment or dementia: a systematic review. Dement Geriatr Cogn Disord 2014;38(5-6):347-365. DOI: 10.1159/000365388.

54. Pitkala K, Savikko N, Poysti M, et al. Efficacy of physical exercise intervention on mobility and physical functioning in older people with dementia: a systematic review. Exp Gerontol 2013;48(1):85-93. DOI: 10.1016/j.exger.2012.08.008.

55. Young J, Angevaren M, Rusted J, et al. Aerobic exercise to improve cognitive function in older people without known cognitive impairment. Cochrane Database Syst Rev 2015(4):CD005381. Available from: http://onlinelibrary.wiley.com/doi/10.1002/14651858. CD005381.pub4/abstract http://onlinelibrary.wiley.com/ store/10.1002/14651858.CD005381.pub4/asset/CD005381.pdf?v=1 $\& t=j 5 i 1 d d y p \& s=d 7 d 9421 e a 5 b d 3 e 124 d 0 e b 1 f c c 8 d d 56 b 0 c 20 b a 1 e 9$.

56. Aguiar EJ, Morgan PJ, Collins CE, et al. Efficacy of interventions that include diet, aerobic and resistance training components for type II 
diabetes prevention: a systematic review with meta-analysis. Int J Behav Nutr Phys Act 2014;11:2. DOI: 10.1186/1479-5868-11-2.

57. Aune $D$, Norat $T$, Leitzmann $M$, et al. Physical activity and the risk of type II diabetes: a systematic review and dose-response metaanalysis. Eur J Epidemiol 2015;30(7):529-542. DOI: 10.1007/s10654015-0056-z.

58. Bain E, Crane M, Tieu J, et al. Diet and exercise interventions for preventing gestational diabetes mellitus. Cochrane Database Syst Rev 2015(4):Cd010443. DOI: 10.1002/14651858.CD010443.pub2.

59. Han S, Middleton P, Crowther CA. Exercise for pregnant women for preventing gestational diabetes mellitus. Cochrane Database Syst Rev 2012(7):CD009021. Available from: http://onlinelibrary.wiley.com/ doi/10.1002/14651858.CD009021.pub2/abstract.

60. Orozco LJ, Buchleitner AM, Gimenez-Perez G, et al. Exercise or exercise and diet for preventing type II diabetes mellitus. Cochrane Database Syst Rev 2008(3):CD003054. DOI: 10.1002/14651858.CD003054.pub3.

61. Arnold CM, Sran MM, Harrison EL. Exercise for fall risk reduction in community-dwelling older adults: a systematic review. Physiother Can 2008;60(4):358-372. DOI: 10.3138/physio.60.4.358.

62. El-Khoury F, Cassou B, Charles MA, et al. The effect of fall prevention exercise programmes on fall induced injuries in community dwelling older adults: systematic review and meta-analysis of randomised controlled trials. BMJ 2013;347:66234.

63. Kendrick D, Kumar A, Carpenter H, et al. Exercise for reducing fear of falling in older people living in the community. Cochrane Database Syst Rev 2014(11):CD009848. Available from: http://onlinelibrary. wiley.com/doi/10.1002/14651858.CD009848.pub2/abstract http:// onlinelibrary.wiley.com/store/10.1002/14651858.CD009848.pub2/ asset/CD009848.pdf? $v=1 \& \mathrm{t}=\mathrm{j} 5 \mathrm{i} 32 \mathrm{t} 6 \mathrm{p} \& \mathrm{~s}=\mathrm{db} 5 \mathrm{e} 4 \mathrm{befae} 355 \mathrm{ed} 88871$ a517e0f6bd474a72f971.

64. Lauersen JB, Bertelsen DM, Andersen LB. The effectiveness of exercise interventions to prevent sports injuries: a systematic review and meta-analysis of randomised controlled trials. Br J Sports Med 2014;48(11):1306-1315. DOI: 10.1136/bjsports-2013-092538.

65. Rössler R, Donath L, Verhagen E, et al. Exercise-based injury prevention in child and adolescent sport: a systematic review and meta-analysis. Sports Med 2014;44(12):1733-1748. DOI: 10.1007/ s40279-014-0234-2.

66. Sherrington C, Whitney JC, Lord SR, et al. Effective exercise for the prevention of falls: a systematic review and meta-analysis. J Am Geriatr Soc 2008;56(12):2234-2243. DOI: 10.1111/j.15325415.2008.02014.x.

67. Cooney GM, Dwan K, Greig CA, et al. Exercise for depression. Cochrane Database Syst Rev 2013(9):CD004366. Available from: http:// onlinelibrary.wiley.com/doi/10.1002/14651858.CD004366.pub6/ abstract http://onlinelibrary.wiley.com/store/10.1002/14651858. CD004366.pub6/asset/CD004366.pdf? $v=1 \& t=j 5 i 3 b 8 h f \& s=f c 5 e a f 1$ 322c811bfcf1ac0f7a1e361d42b8bdb85.

68. Daley A, Jolly K, MacArthur C. The effectiveness of exercise in the management of post-natal depression: systematic review and meta-analysis. Family Pract 2009;26(2):154-162. DOI: 10.1093/fampra/ cmn101.

69. de Souza Moura AM, Lamego MK, Paes F, et al. Effects of aerobic exercise on anxiety disorders: a systematic review. CNS Neurol Disord Drug Targets 2015;14(9):1184-1193. DOI: 10.2174/18715273156661511 11121259.

70. Firth J, Stubbs B, Rosenbaum S, et al. Aerobic exercise improves cognitive functioning in people with schizophrenia: a systematic review and meta-analysis. Schizophr Bull 2017;43(3):546-556.

71. Gorczynski P, Faulkner G. Exercise therapy for schizophrenia. Cochrane Database Syst Rev 2010(5):Cd004412. DOI: 10.1002/14651858. CD004412.pub2.

72. Herring MP, O'Connor PJ, Dishman RK. The effect of exercise training on anxiety symptoms among patients: a systematic review. Arch Intern Med 2010;170(4):321-331. DOI: 10.1001/archinternmed. 2009.530.
73. Jayakody K, Gunadasa S, Hosker C. Exercise for anxiety disorders: systematic review. Br J Sports Med 2014;48(3):187-196. DOI: 10.1136/ bjsports-2012-091287.

74. Josefsson $T$, Lindwall $M$, Archer T. Physical exercise intervention in depressive disorders: meta-analysis and systematic review. Scand J Med Sci Sports 2014;24(2):259-272. DOI: 10.1111/sms.12050.

75. McCurdy AP, Boule NG, Sivak A, et al. Effects of exercise on mildto-moderate depressive symptoms in the postpartum period: a meta-analysis. Obstet Gynecol 2017;129(6):1087-1097. DOI: 10.1097/ AOG.0000000000002053.

76. Mochcovitch MD, Deslandes AC, Freire RC, et al. The effects of regular physical activity on anxiety symptoms in healthy older adults: a systematic review. Braz J Psychiatry 2016;38(3):255-261. DOI: 10.1590/1516-4446-2015-1893.

77. Stonerock GL, Hoffman BM, Smith PJ, et al. Exercise as treatment for anxiety: systematic review and analysis. Ann Behav Med 2015;49(4):542-556. DOI: 10.1007/s12160-014-9685-9.

78. Garcia-Hermoso A, Sanchez-Lopez M, Martinez-Vizcaino V. Effects of aerobic plus resistance exercise on body composition related variables in pediatric obesity: a systematic review and meta-analysis of randomized controlled trials. Pediatr Exerc Sci 2015;27(4):431-440. DOI: 10.1123/pes.2014-0132.

79. Ho M, Garnett SP, Baur LA, et al. Impact of dietary and exercise interventions on weight change and metabolic outcomes in obese children and adolescents: a systematic review and meta-analysis of randomized trials. JAMA Pediatr 2013;167(8):759-768. DOI: 10.1001/ jamapediatrics.2013.1453.

80. Kelley GA, Kelley KS. Effects of exercise in the treatment of overweight and obese children and adolescents: a systematic review of metaanalyses. J Obes 2013;2013:783103. DOI: 10.1155/2013/783103.

81. Kelley GA, Kelley KS, Pate RR. Exercise and BMI in overweight and obese children and adolescents: a systematic review and trial sequential meta-analysis. Biomed Res Int 2015;2015:704539. DOI: 10.1155/2015/704539.

82. Södlerlund A, Fischer A, Johansson T, et al. Physical activity, diet and behaviour modification in the treatment of overweight and obese adults: a systematic review. Perspect Public Health 2009;129(3): 132-142. DOI: 10.1177/1757913908094805.

83. Drawer S, Fuller CW. Propensity for osteoarthritis and lower limb joint pain in retired professional soccer players. $\mathrm{Br} J$ Sports Med 2001;35(6):402-408. DOI: 10.1136/bjsm.35.6.402.

84. Gouttebarge V, Inklaar H, Frings-Dresen MH. Risk and consequences of osteoarthritis after a professional football career: a systematic review of the recent literature. J Sports Med Phys Fitness 2014;54(4): 494-504.

85. Tran G, Smith TO, Grice A, et al. Does sports participation (including level of performance and previous injury) increase risk of osteoarthritis? A systematic review and meta-analysis. Br J Sports Med 2016;50(23):1459-1466. DOI: 10.1136/bjsports-2016-096142.

86. Lavie CJ, O'Keefe JH, Sallis RE. Exercise and the heart-the harm of too little and too much. Curr Sports Med Rep 2015;14(2):104-109. DOI: 10.1249/JSR.0000000000000134.

87. McCrory P, Meeuwisse WH, Kutcher JS, et al. What is the evidence for chronic concussion-related changes in retired athletes: behavioural, pathological and clinical outcomes? Br J Sports Med 2013;47(5):327330. DOI: 10.1136/bjsports-2013-092248.

88. Janssen KW, Orchard JW, Driscoll TR, et al. High incidence and costs for anterior cruciate ligament reconstructions performed in Australia from 2003-2004 to 2007-2008: time for an anterior cruciate ligament register by Scandinavian model? Scand J Med Sci Sports 2012;22(4):495-501. DOI: 10.1111/j.1600-0838.2010.01253.x.

89. Sharma S, Merghani A, Mont L. Exercise and the heart: the good, the bad, and the ugly. Eur Heart J 2015;36(23):1445-1453. DOI: 10.1093/ eurheartj/ehv090.

90. Regnaux JP, Lefevre-Colau MM, Trinquart L, et al. High-intensity vs low-intensity physical activity or exercise in people with hip or knee 
osteoarthritis. Cochrane Database Syst Rev 2015;10:Cd010203. DOI: 10.1002/14651858.CD010203.pub2.

91. Lee IM, Paffenbarger Jr RS. Physical activity and stroke incidence: the Harvard Alumni health study. Stroke 1998;29(10):2049-2054. DOI: 10.1161/01.STR.29.10.2049.

92. Australian Bureau of Statistics (AU). Dementia and deaths in Australia Canberra: Australian Bureau of Statistics; 2017 Available from: http://www.abs.gov.au/ausstats/abs@.nsf/Lookup/by\%20 Subject/3303.0 2015 Main\%20Features Dementia 10002.

93. National preventative taskforce.

94. Department of Health (AU). Tobacco Control key facts and figures Canberra Department of Health 2017 Available from: http://www.health.gov.au/internet/main/publishing.nsf/content/ tobacco-kff. 
Appendix A: Inclusion/exclusion criteria for “Exercise as medicine-evidence for prescribing exercise for Australia's nine national health priority areas: an umbrella review"

\begin{tabular}{|c|c|c|c|}
\hline & Inclusion criteria & Exclusion criteria & Rationale for this criteria \\
\hline Publication type & $\begin{array}{l}\text { Peer-reviewed systematic } \\
\text { review and/or meta-analysis } \\
\text { articles only. }\end{array}$ & $\begin{array}{l}\text { All other publications including peer- } \\
\text { reviewed original research papers, } \\
\text { observational studies, non-peer-reviewed } \\
\text { articles, newspapers, opinion pieces, } \\
\text { editorials, commentaries and letters to the } \\
\text { editor. } \\
\text { Conference proceedings/abstracts. } \\
\text { Book chapters. }\end{array}$ & $\begin{array}{l}\text { Aim of the umbrella review is to synthesize } \\
\text { the existing evidence. } \\
\text { Where there were two or more studies avail- } \\
\text { able on the same topic, the AMSTAR rating } \\
\text { was used. }\end{array}$ \\
\hline Language & English language & Non-English & $\begin{array}{l}\text { For reasons of practicality, it was deemed } \\
\text { acceptable to include only studies published } \\
\text { in English. }\end{array}$ \\
\hline Publication date & 2007 to 2017 & Publications prior to 2007. & $\begin{array}{l}\text { To ensure up to- date publications are } \\
\text { assessed and reflect the increasing under- } \\
\text { standing within the literature and in clinical } \\
\text { practice that exercise is medicine. }\end{array}$ \\
\hline $\begin{array}{l}\text { The National } \\
\text { Health Priority } \\
\text { Areas (NHPAs) }\end{array}$ & $\begin{array}{l}\text { Arthritis and musculoskel- } \\
\text { etal conditions, asthma, } \\
\text { dementia, diabetes mellitus, } \\
\text { cancer control, cardiovascu- } \\
\text { lar health, injury prevention } \\
\text { and control, mental health, } \\
\text { obesity }\end{array}$ & $\begin{array}{l}\text { Any other condition other than arthritis } \\
\text { and musculoskeletal conditions, asthma, } \\
\text { dementia, diabetes mellitus, cancer } \\
\text { control, cardiovascular health, injury } \\
\text { prevention and control, mental health, } \\
\text { and obesity. For example, if the study is re- } \\
\text { lating to lipid profiles, then excluded from } \\
\text { this umbrella review as the aim of this } \\
\text { umbrella review is to look at the NHPA/ } \\
\text { primary problem. }\end{array}$ & $\begin{array}{l}\text { The NHPAs were established in response to } \\
\text { the World Health Organization's global strat- } \\
\text { egy Health for All by the year 2000. Arthritis } \\
\text { and musculoskeletal conditions, asthma, } \\
\text { cancer control, cardiovascular health, demen- } \\
\text { tia, diabetes mellitus, injury prevention and } \\
\text { control, mental health, and obesity are the } \\
\text { nine NHPAs that contribute to the burden of } \\
\text { disease in Australia. } \\
\text { The aim of this umbrella review was to } \\
\text { examine the empirically published literature } \\
\text { to describe the relationship between exercise } \\
\text { and the nine NHPA's. }\end{array}$ \\
\hline $\begin{array}{l}\text { Outcome } \\
\text { measures }\end{array}$ & $\begin{array}{l}\text { Role of exercise in the } \\
\text { management of the } \\
\text { condition. } \\
\text { Role of exercise in the } \\
\text { treatment of the condition. } \\
\text { Role of exercise in the QOL, } \\
\text { well-being, and fitness } \\
\text { levels. } \\
\text { Role of exercise in the } \\
\text { prevention of the condition. }\end{array}$ & $\begin{array}{l}\text { - Role of exercise in the management of } \\
\text { the condition. } \\
\text { - Role of exercise in the treatment of } \\
\text { the condition. } \\
\text { - Role of exercise in the QOL, well-being, } \\
\text { and fitness levels., }\end{array}$ & $\begin{array}{l}\text { The primary outcomes of interest are the role } \\
\text { of exercise in management, treatment, and } \\
\text { prevention of the nine NHPA's. } \\
\text { To assist in the management and prevention } \\
\text { of chronic disease. }\end{array}$ \\
\hline
\end{tabular}

Appendix B: Umbrella review search strategy

\begin{tabular}{|c|c|c|c|c|}
\hline Database & $\begin{array}{l}\text { Health priority } \\
\text { area }\end{array}$ & Search terms & Applied filters & Results \\
\hline \multirow[t]{4}{*}{$\begin{array}{l}\text { CINAHL plus } \\
\text { with Fill Text } \\
\text { (EBSCOhost) }\end{array}$} & $\begin{array}{l}\text { Arthritis and } \\
\text { musculoskeletal } \\
\text { conditions }\end{array}$ & $\begin{array}{l}\text { AB ((arthritis OR musculoskeletal OR osteoporosis OR osteoar- } \\
\text { thritis OR back pain OR gout) AND exercise) AND AB (prevention } \\
\text { OR risk factor OR treatment OR management) AND (systematic } \\
\text { review OR meta-analysis) }\end{array}$ & \multirow{4}{*}{$\begin{array}{l}\text { Year filter (2007- } \\
2017 \text { ) } \\
\text { Human } \\
\text { Language filter } \\
\text { (English) } \\
\text { Systematic review } \\
\text { OR meta-analysis }\end{array}$} & 133 \\
\hline & Asthma & $\begin{array}{l}\text { AB ((asthma) AND exercise) AND AB (prevention OR risk factor } \\
\text { OR treatment OR management) AND (systematic review OR } \\
\text { meta-analysis) }\end{array}$ & & 14 \\
\hline & Cancer control & $\begin{array}{l}\text { AB ((cancer) AND exercise) AND AB (prevention OR risk factor } \\
\text { OR treatment OR management) AND (systematic review OR } \\
\text { meta-analysis) }\end{array}$ & & 89 \\
\hline & $\begin{array}{l}\text { Cardiovascular } \\
\text { health }\end{array}$ & $\begin{array}{l}\text { AB ((cardio* OR cardiac* OR stroke OR thrombo*) AND exercise) } \\
\text { AND AB (prevention OR risk factor OR treatment OR manage- } \\
\text { ment) AND (systematic review OR meta-analysis) }\end{array}$ & & 134 \\
\hline
\end{tabular}




\begin{tabular}{|c|c|c|c|c|}
\hline Database & $\begin{array}{l}\text { Health priority } \\
\text { area }\end{array}$ & Search terms & Applied filters & Results \\
\hline & Dementia & $\begin{array}{l}\text { AB ((dementia) AND exercise) AND AB (prevention OR risk factor } \\
\text { OR treatment OR management) AND (systematic review OR } \\
\text { meta-analysis) }\end{array}$ & & 13 \\
\hline & Diabetes & $\begin{array}{l}\text { AB ((diab*) AND exercise) AND AB (prevention OR risk factor OR } \\
\text { treatment OR management) AND (systematic review OR meta- } \\
\text { analysis) }\end{array}$ & & 69 \\
\hline & $\begin{array}{l}\text { Injury preven- } \\
\text { tion and control }\end{array}$ & $\begin{array}{l}A B \text { ((injury prevention OR fall) AND exercise) AND AB (preven- } \\
\text { tion OR risk factor OR treatment OR management) AND (system- } \\
\text { atic review OR meta-analysis) }\end{array}$ & & 65 \\
\hline & Mental health & $\begin{array}{l}\text { AB ((mental health OR depress* OR schizophrenia OR anxiety) } \\
\text { AND exercise) AND AB (prevention OR risk factor OR treatment } \\
\text { OR management) AND (systematic review OR meta-analysis) }\end{array}$ & & 77 \\
\hline & Obesity & $\begin{array}{l}\text { AB ((obesity OR obese OR overweight) AND exercise) AND AB } \\
\text { (prevention OR risk factor OR treatment OR management) AND } \\
\text { (systematic review OR meta-analysis) }\end{array}$ & & 38 \\
\hline \multirow[t]{9}{*}{$\begin{array}{l}\text { Cochrane Data- } \\
\text { base of System- } \\
\text { atic Reviews }\end{array}$} & $\begin{array}{l}\text { Arthritis and } \\
\text { musculoskeletal } \\
\text { conditions }\end{array}$ & $\begin{array}{l}\text { (arthritis OR musculoskeletal OR osteoporosis OR osteoarthritis } \\
\text { OR back pain OR gout) AND exercise in Title, Abstract, Keywords } \\
\text { and risk factor OR prevention OR management OR treatment in } \\
\text { Title, Abstract, Keywords }\end{array}$ & $\begin{array}{l}\text { Year filter (2007- } \\
\text { 2017), Human, Lan- } \\
\text { guage filter (English) }\end{array}$ & 89 \\
\hline & Asthma & $\begin{array}{l}\text { asthma AND exercise in Title, Abstract, Keywords and risk factor } \\
\text { OR prevention OR management OR treatment in Title, Abstract, } \\
\text { Keywords and }\end{array}$ & & 21 \\
\hline & Cancer control & $\begin{array}{l}\text { Cancer AND exercise in Title, Abstract, Keywords and risk factor } \\
\text { OR prevention OR management OR treatment in Title, Abstract, } \\
\text { Keywords }\end{array}$ & & 36 \\
\hline & $\begin{array}{l}\text { Cardiovascular } \\
\text { health }\end{array}$ & $\begin{array}{l}\text { (cardio* OR cardiac* OR stroke OR thrombo) AND exercise in } \\
\text { Title, Abstract, Keywords and risk factor OR prevention OR man- } \\
\text { agement OR treatment in Title, Abstract, Keywords }\end{array}$ & & 103 \\
\hline & Dementia & $\begin{array}{l}\text { dementia AND exercise in Title, Abstract, Keywords and risk } \\
\text { factor OR prevention OR management OR treatment in Title, } \\
\text { Abstract, Keywords }\end{array}$ & & 7 \\
\hline & Diabetes & $\begin{array}{l}\text { Diabet* AND exercise in Title, Abstract, Keywords and risk factor } \\
\text { OR prevention OR management OR treatment in Title, Abstract, } \\
\text { Keywords }\end{array}$ & & 41 \\
\hline & $\begin{array}{l}\text { Injury preven- } \\
\text { tion and control }\end{array}$ & $\begin{array}{l}\text { (injury prevention OR falls) AND exercise in Title, Abstract, } \\
\text { Keywords and risk factor OR prevention OR management OR } \\
\text { treatment in Title, Abstract, Keywords }\end{array}$ & & 42 \\
\hline & Mental health & $\begin{array}{l}\text { (mental health OR depress* OR anxiety OR suicide OR schizo- } \\
\text { phrenia) AND exercise in Title, Abstract, Keywords and risk factor } \\
\text { OR prevention OR management OR treatment in Title, Abstract, } \\
\text { Keywords }\end{array}$ & & 77 \\
\hline & Obesity & $\begin{array}{l}\text { (obesity OR obese OR overweight) AND exercise in Record Title } \\
\text { and systematic review OR meta-analysis in Title, Abstract, Key- } \\
\text { words and prevention OR risk factor OR treatment OR manage- } \\
\text { ment in Title, Abstract, Keywords }\end{array}$ & & 29 \\
\hline \multirow[t]{3}{*}{$\begin{array}{l}\text { PubMed (with } \\
\text { Medline) }\end{array}$} & $\begin{array}{l}\text { Arthritis and } \\
\text { musculoskeletal } \\
\text { conditions }\end{array}$ & $\begin{array}{l}\text { arthritis(title/abstract) OR osteoporosis(title/abstract) OR } \\
\text { back pain(title/abstract) OR osteoarthritis(title/abstract) OR } \\
\text { gout(title/abstract) AND exercise (title/abstract) AND (preven- } \\
\text { tion OR risk factor OR treatment OR management) AND (system- } \\
\text { atic review OR meta-analysis) AND Review (ptyp) }\end{array}$ & \multirow{3}{*}{$\begin{array}{l}\text { Year filter (2007 - } \\
\text { 2017) } \\
\text { Human } \\
\text { Language filter } \\
\text { (English), System- } \\
\text { atic reviews or meta- } \\
\text { analysis }\end{array}$} & 349 \\
\hline & Asthma & $\begin{array}{l}\text { asthma(title/abstract) AND exercise (title/abstract) AND } \\
\text { (prevention OR risk factor OR treatment OR management) AND } \\
\text { (systematic review OR meta-analysis) AND Review (ptyp) }\end{array}$ & & 44 \\
\hline & Cancer control & $\begin{array}{l}\text { cancer(title/abstract) AND exercise (title/abstract) AND (preven- } \\
\text { tion OR risk factor OR treatment OR management) AND (system- } \\
\text { atic review OR meta-analysis) AND Review (ptyp) }\end{array}$ & & 241 \\
\hline
\end{tabular}


Contd...

\begin{tabular}{|c|c|c|c|c|}
\hline Database & $\begin{array}{l}\text { Health priority } \\
\text { area }\end{array}$ & Search terms & Applied filters & Results \\
\hline & $\begin{array}{l}\text { Cardiovascular } \\
\text { health }\end{array}$ & $\begin{array}{l}\text { cardiac*(title/abstract) OR cardio*(title/abstract) OR stroke(title/ } \\
\text { abstract) OR thrombo*(title/abstract) AND exercise (title/ab- } \\
\text { stract) AND (prevention OR risk factor OR treatment OR manage- } \\
\text { ment) AND (systematic review OR meta-analysis) AND Review } \\
\text { (ptyp) }\end{array}$ & & 328 \\
\hline & Dementia & $\begin{array}{l}\text { dementia(title/abstract) OR Alzheimer's (title/abnstract) AND } \\
\text { exercise (title/abstract) AND (prevention OR risk factor OR } \\
\text { treatment OR management) AND (systematic review OR meta- } \\
\text { analysis) AND Review (ptyp) }\end{array}$ & & 51 \\
\hline & Diabetes & 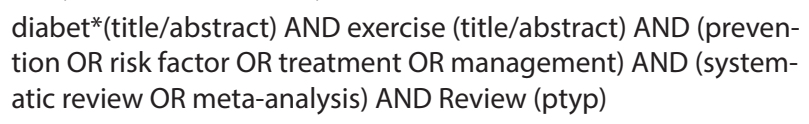 & & 233 \\
\hline & $\begin{array}{l}\text { Injury preven- } \\
\text { tion and control }\end{array}$ & $\begin{array}{l}\text { injury prevention(title/abstract) OR fall(title/abstract) AND exer- } \\
\text { cise (title/abstract) AND (prevention OR risk factor OR treatment } \\
\text { OR management) AND (systematic review OR meta-analysis) } \\
\text { AND Review (ptyp) }\end{array}$ & & 87 \\
\hline & Mental health & $\begin{array}{l}\text { mental health(title/abstract) OR depressi*(title/abstract) } \\
\text { OR anxiety(title/abstract) OR suicide(title/abstract) OR } \\
\text { schizophrenia(title/abstract) AND exercise (title/abstract) AND } \\
\text { (prevention OR risk factor OR treatment OR management) AND } \\
\text { (systematic review OR meta-analysis) AND Review (ptyp) }\end{array}$ & & 317 \\
\hline & Obesity & $\begin{array}{l}\text { obesity(title/abstract) OR obese(title/abstract) OR } \\
\text { overweight(title/abstract) AND exercise (title/abstract) AND } \\
\text { (prevention OR risk factor OR treatment OR management) AND } \\
\text { (systematic review OR meta-analysis) AND Review (ptyp) }\end{array}$ & & 229 \\
\hline \multirow[t]{9}{*}{ SPORTDiscus } & $\begin{array}{l}\text { Arthritis and } \\
\text { musculoskeletal } \\
\text { conditions }\end{array}$ & $\begin{array}{l}\text { AB ((arthritis OR musculoskeletal OR osteoporosis OR osteoar- } \\
\text { thritis OR back pain OR gout) AND exercise) AND AB (prevention } \\
\text { OR risk factor OR treatment OR management) AND (systematic } \\
\text { review OR meta-analysis) }\end{array}$ & \multirow{9}{*}{$\begin{array}{l}\text { Year filter (2007- } \\
\text { 2017) } \\
\text { Human } \\
\text { Language filter } \\
\text { (English) } \\
\text { Journal article } \\
\text { Peer-reviewed }\end{array}$} & 85 \\
\hline & Asthma & $\begin{array}{l}\text { AB ((asthma) AND exercise) AND AB (prevention OR risk factor } \\
\text { OR treatment OR management) AND (systematic review OR } \\
\text { meta-analysis) }\end{array}$ & & 1 \\
\hline & Cancer control & $\begin{array}{l}\text { AB ((cancer) AND exercise) AND AB (prevention OR risk factor } \\
\text { OR treatment OR management) AND (systematic review OR } \\
\text { meta-analysis) }\end{array}$ & & 24 \\
\hline & $\begin{array}{l}\text { Cardiovascular } \\
\text { health }\end{array}$ & $\begin{array}{l}\text { AB ((cardio* OR cardiac* OR stroke OR thrombo*) AND exercise) } \\
\text { AND AB (prevention OR risk factor OR treatment OR manage- } \\
\text { ment) AND (systematic review OR meta-analysis) }\end{array}$ & & 48 \\
\hline & Dementia & $\begin{array}{l}\text { AB ((dementia) AND exercise) AND AB (prevention OR risk factor } \\
\text { OR treatment OR management) AND (systematic review OR } \\
\text { meta-analysis) }\end{array}$ & & 1 \\
\hline & Diabetes & $\begin{array}{l}\text { AB ((diab*) AND exercise) AND AB (prevention OR risk factor OR } \\
\text { treatment OR management) AND (systematic review OR meta- } \\
\text { analysis) }\end{array}$ & & 13 \\
\hline & $\begin{array}{l}\text { Injury preven- } \\
\text { tion and control }\end{array}$ & $\begin{array}{l}\text { AB ((injury prevention OR fall) AND exercise) AND AB (preven- } \\
\text { tion OR risk factor OR treatment OR management) AND (system- } \\
\text { atic review OR meta-analysis) }\end{array}$ & & 36 \\
\hline & Mental health & $\begin{array}{l}\text { AB ((mental health OR depress* OR schizophrenia OR anxiety) } \\
\text { AND exercise) AND AB (prevention OR risk factor OR treatment } \\
\text { OR management) AND (systematic review OR meta-analysis) }\end{array}$ & & 31 \\
\hline & Obesity & $\begin{array}{l}\text { AB ((obesity OR obese OR overweight) AND exercise) AND AB } \\
\text { (prevention OR risk factor OR treatment OR management) AND } \\
\text { (systematic review OR meta-analysis) }\end{array}$ & & 14 \\
\hline
\end{tabular}




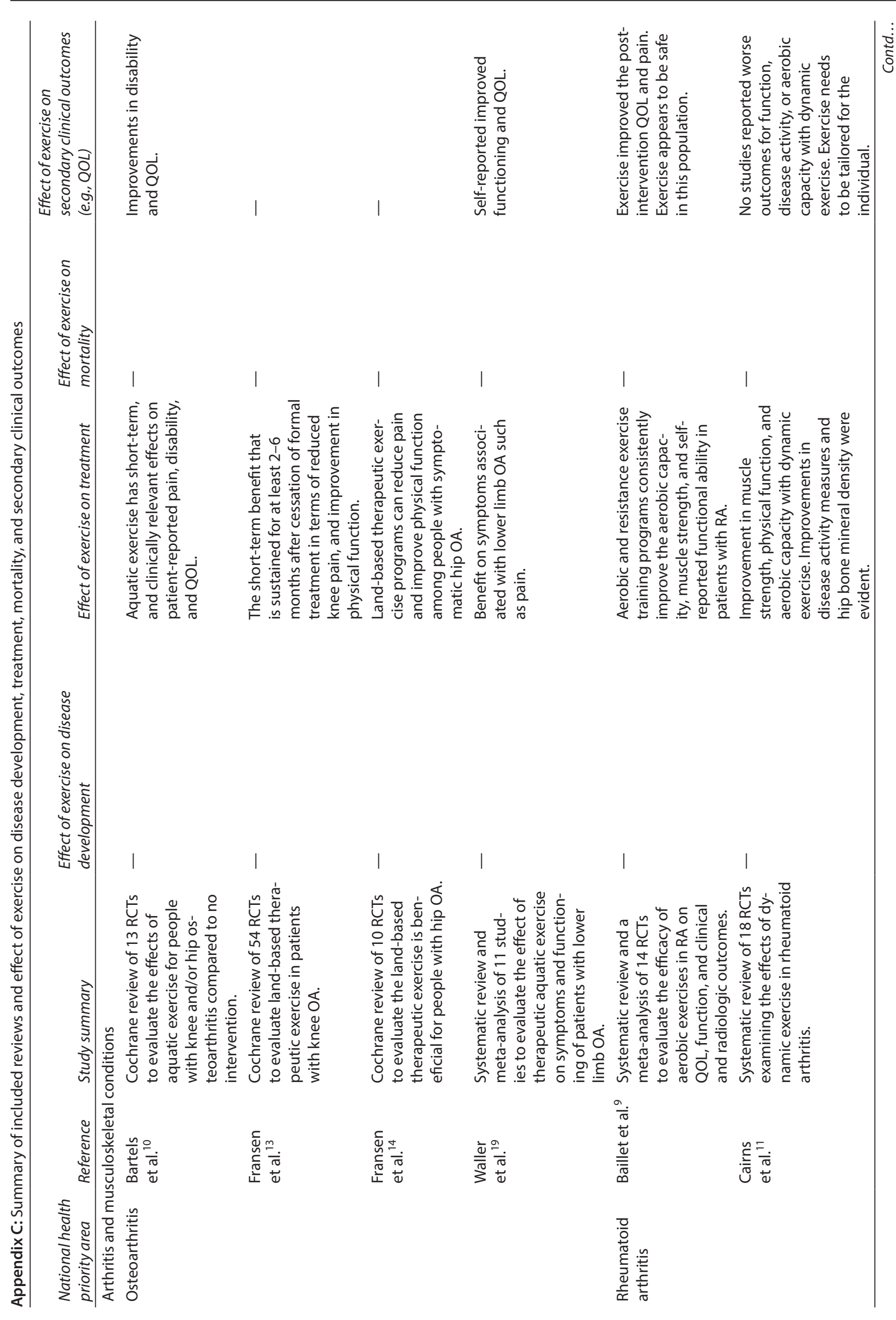




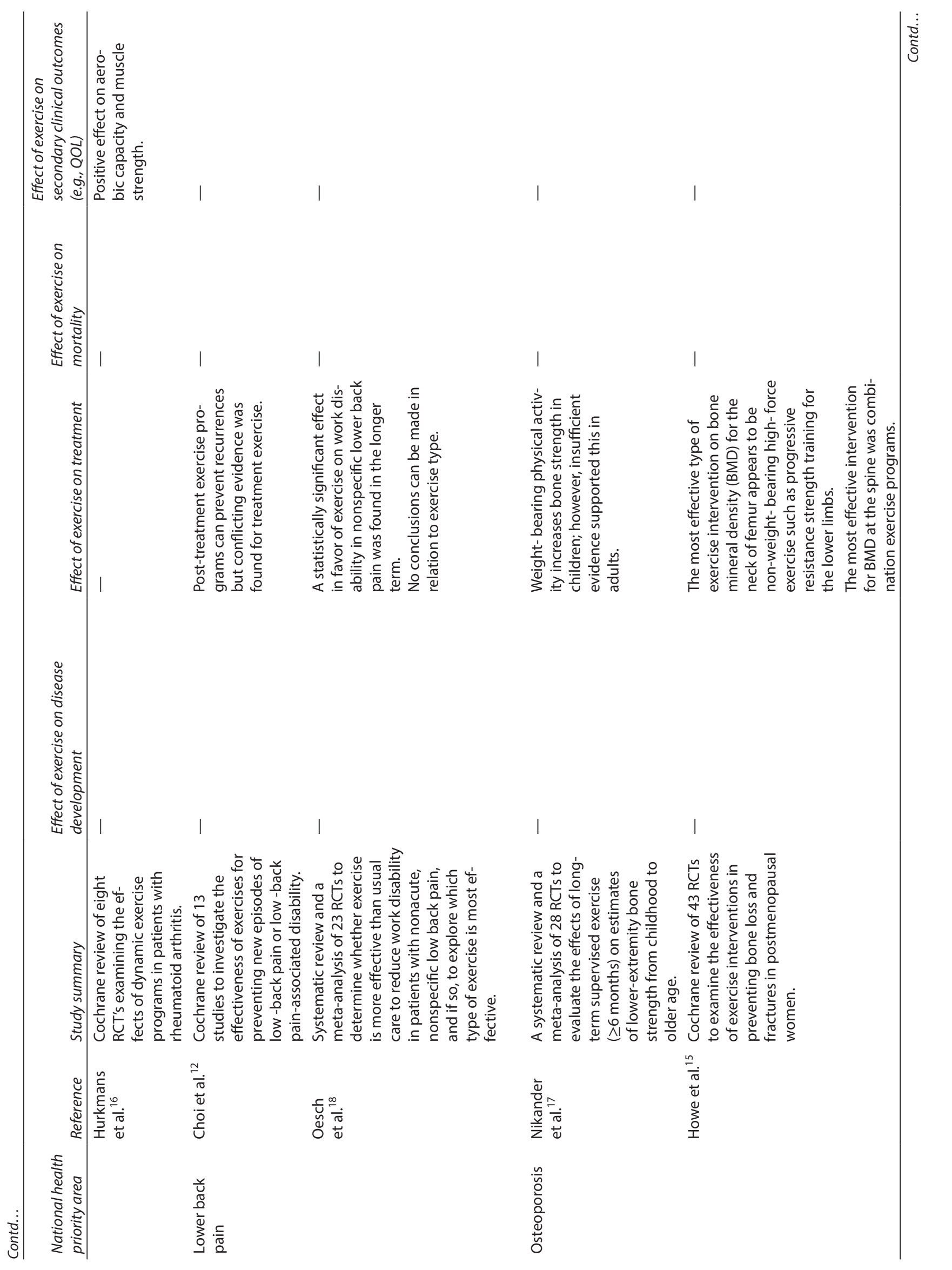




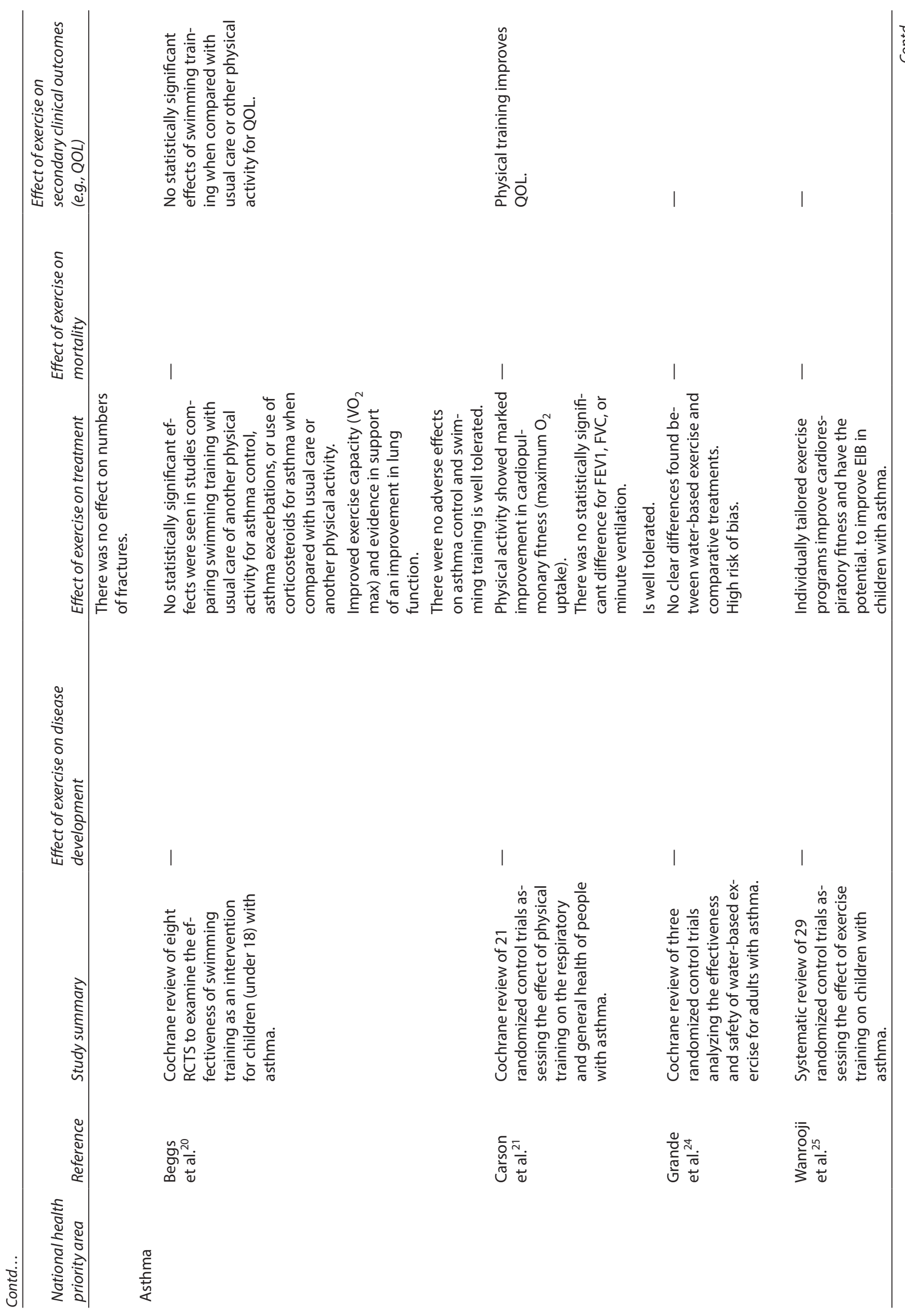




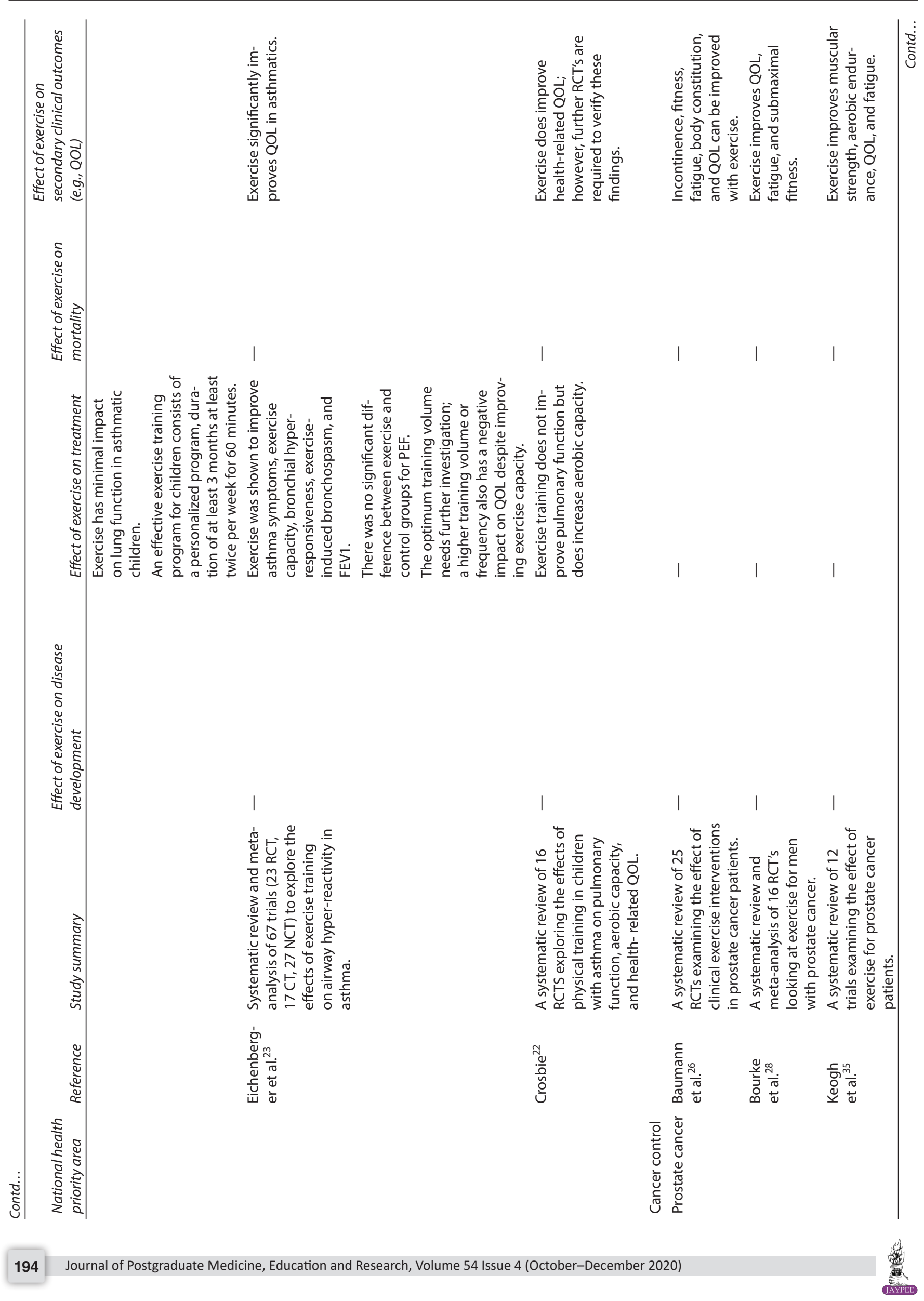




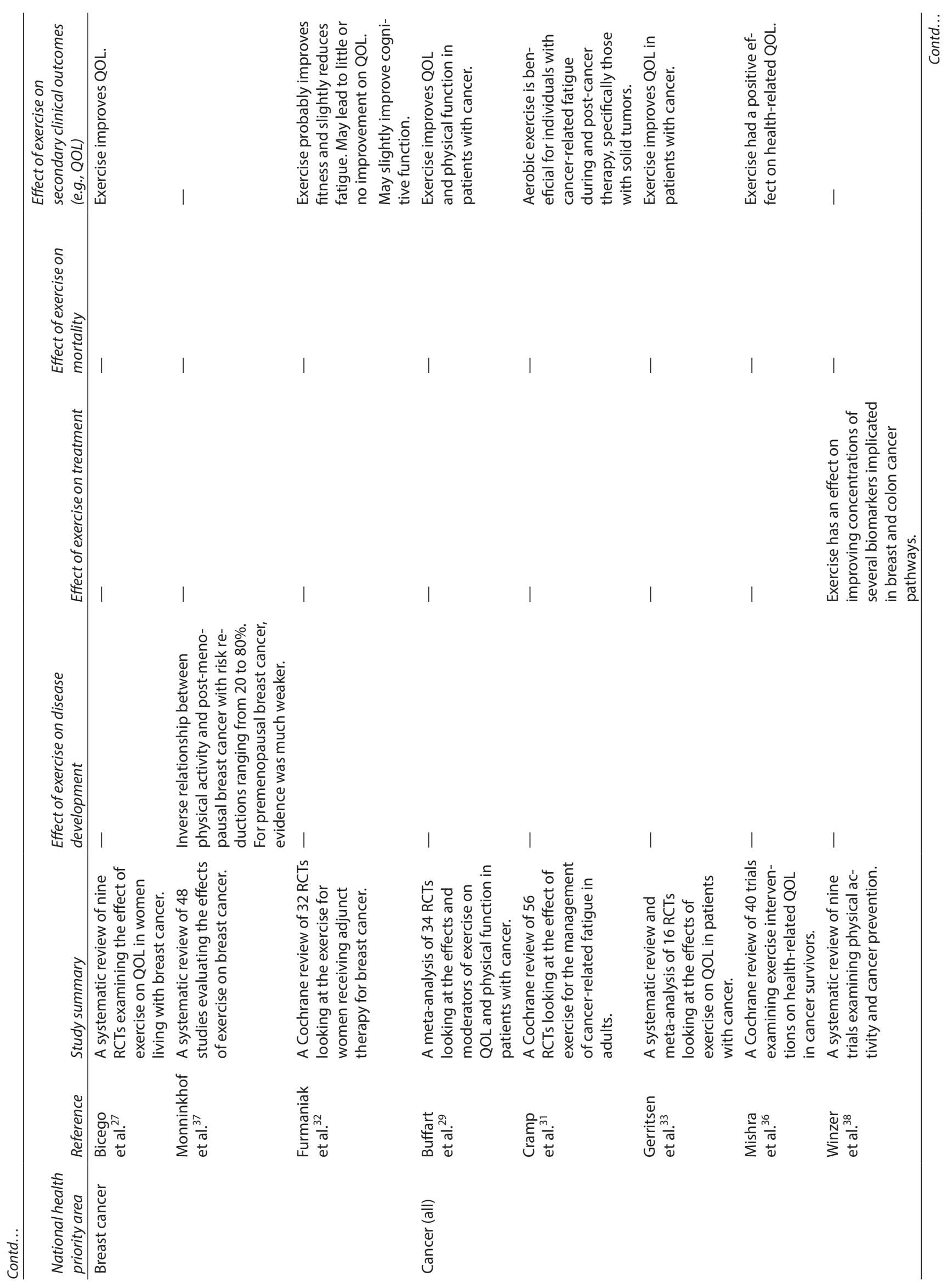




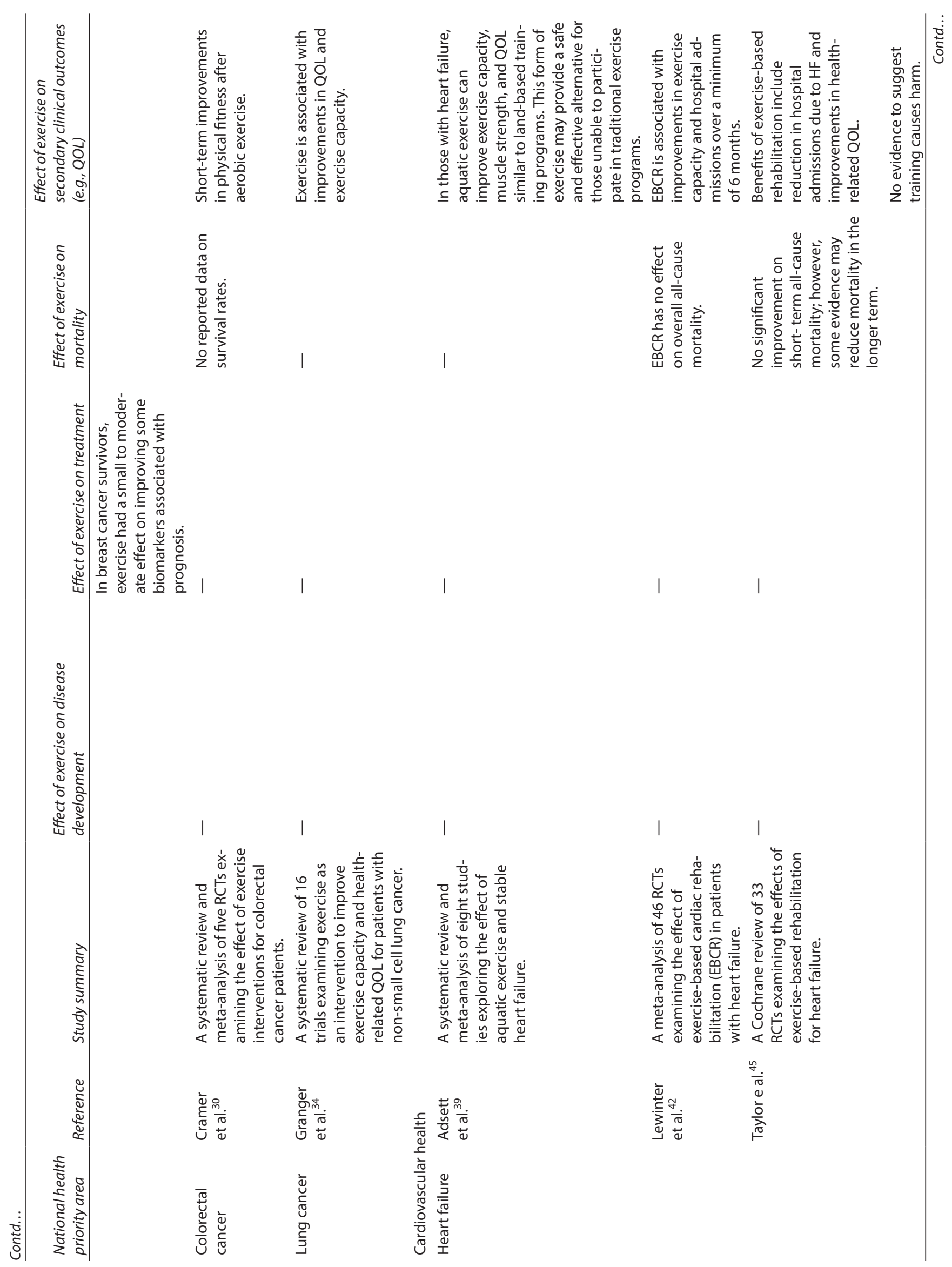




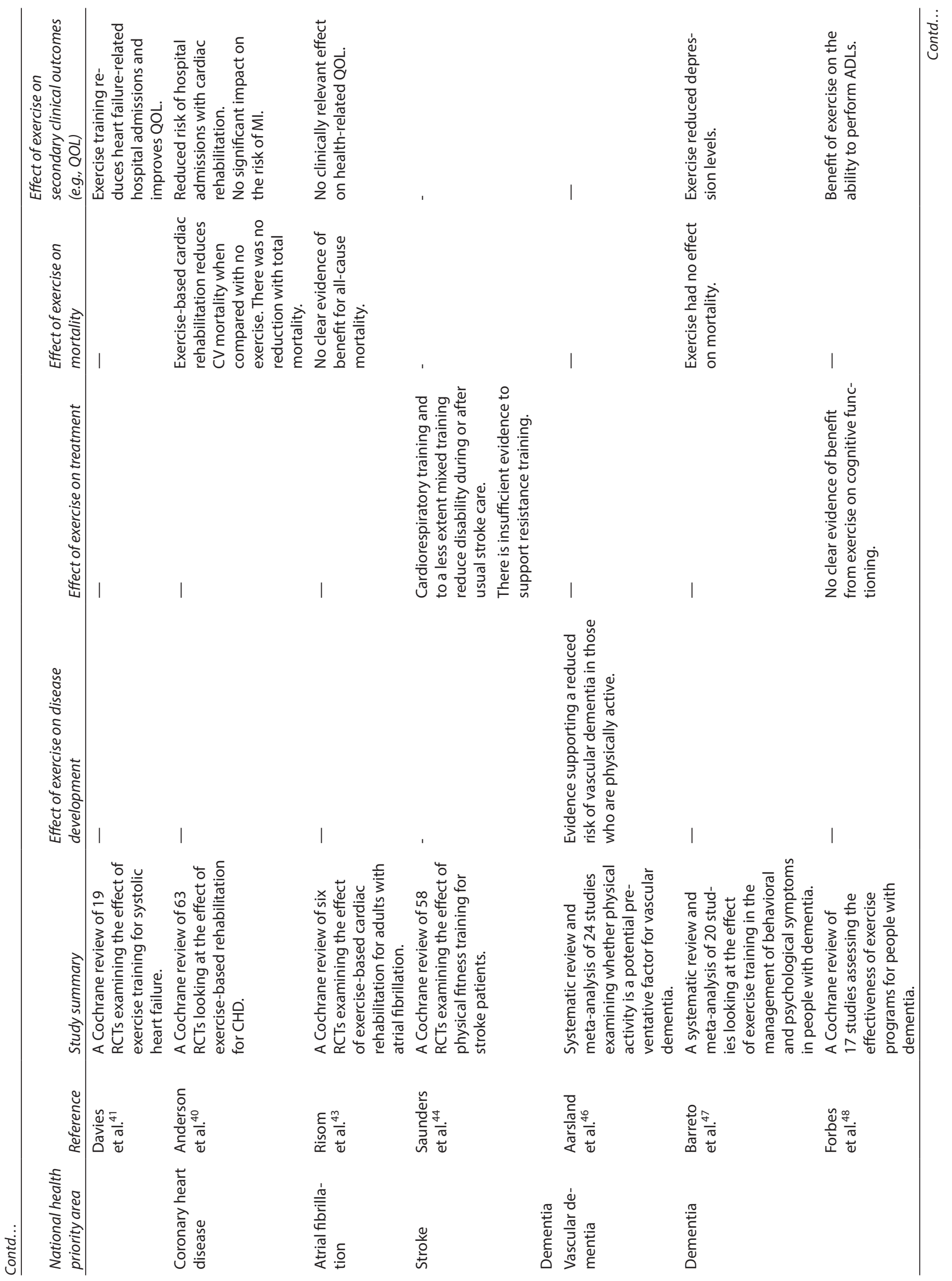




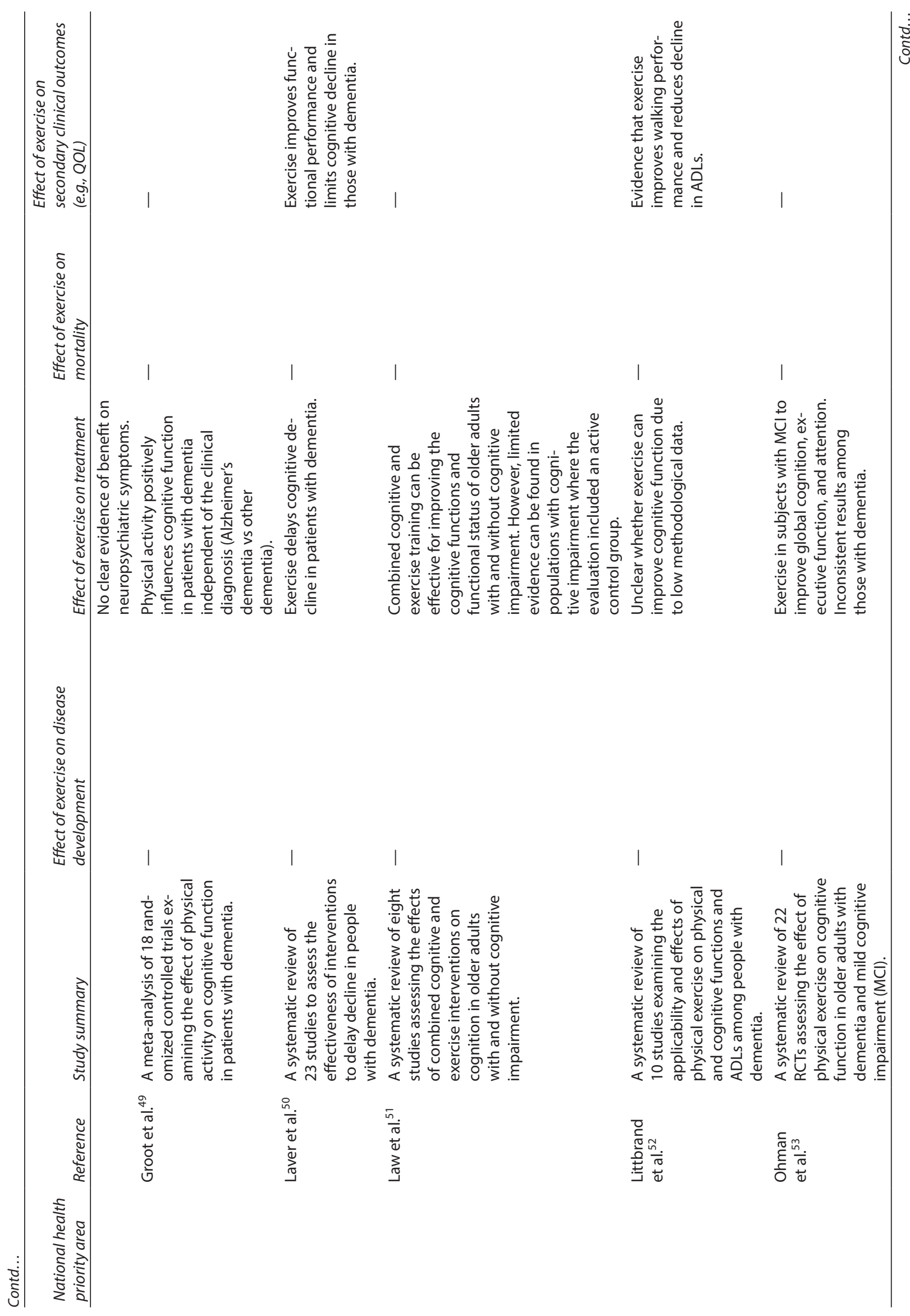




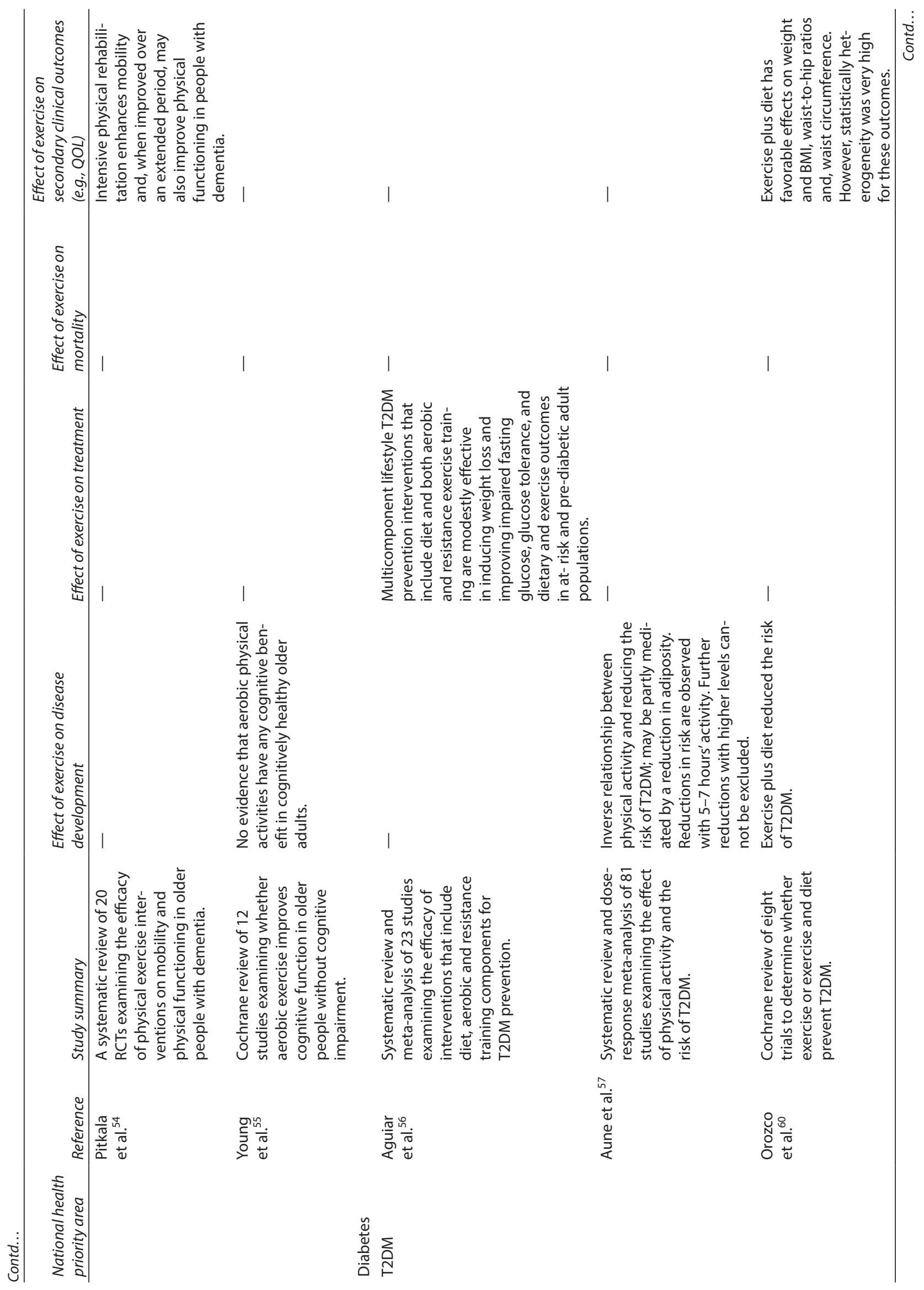




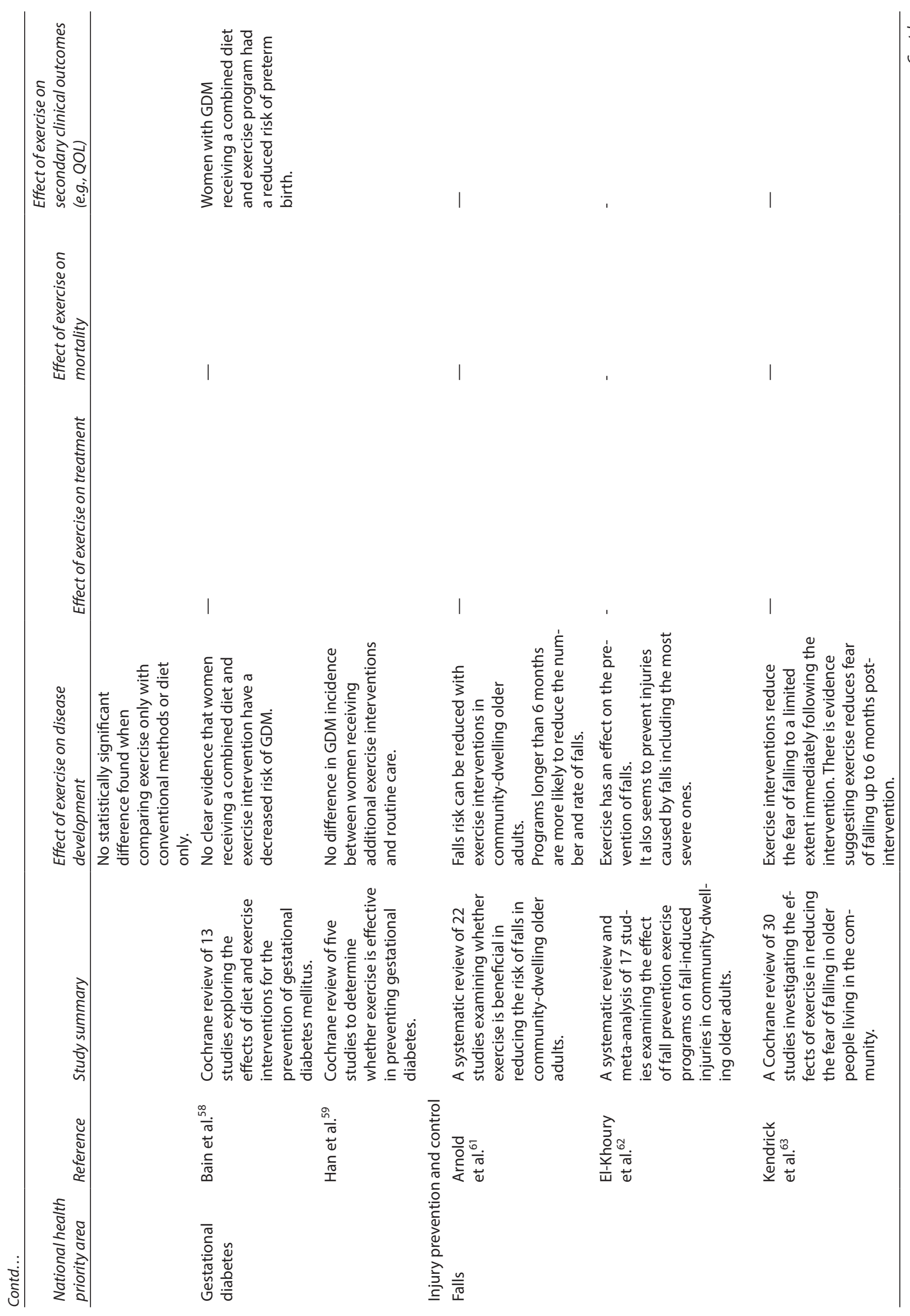




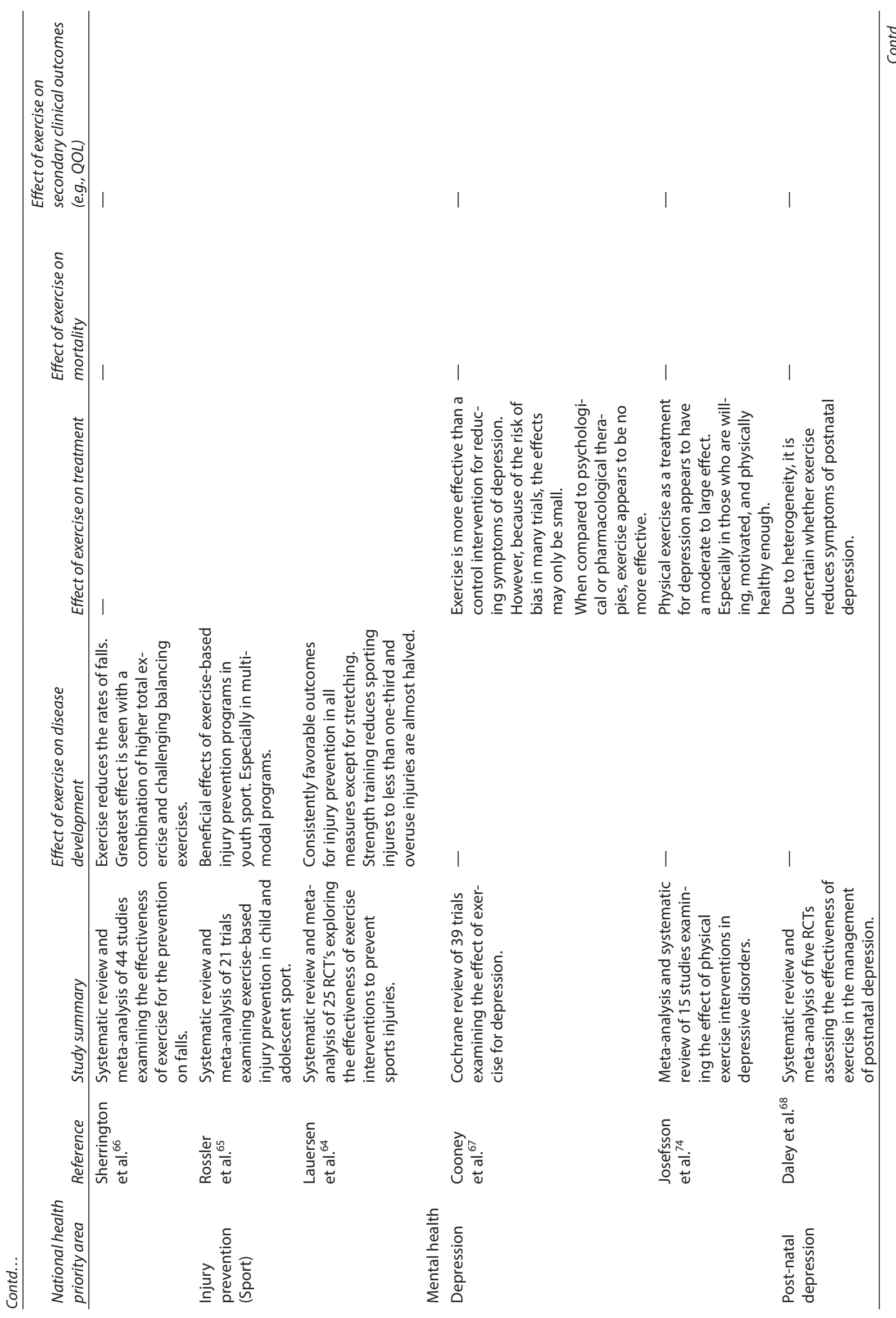




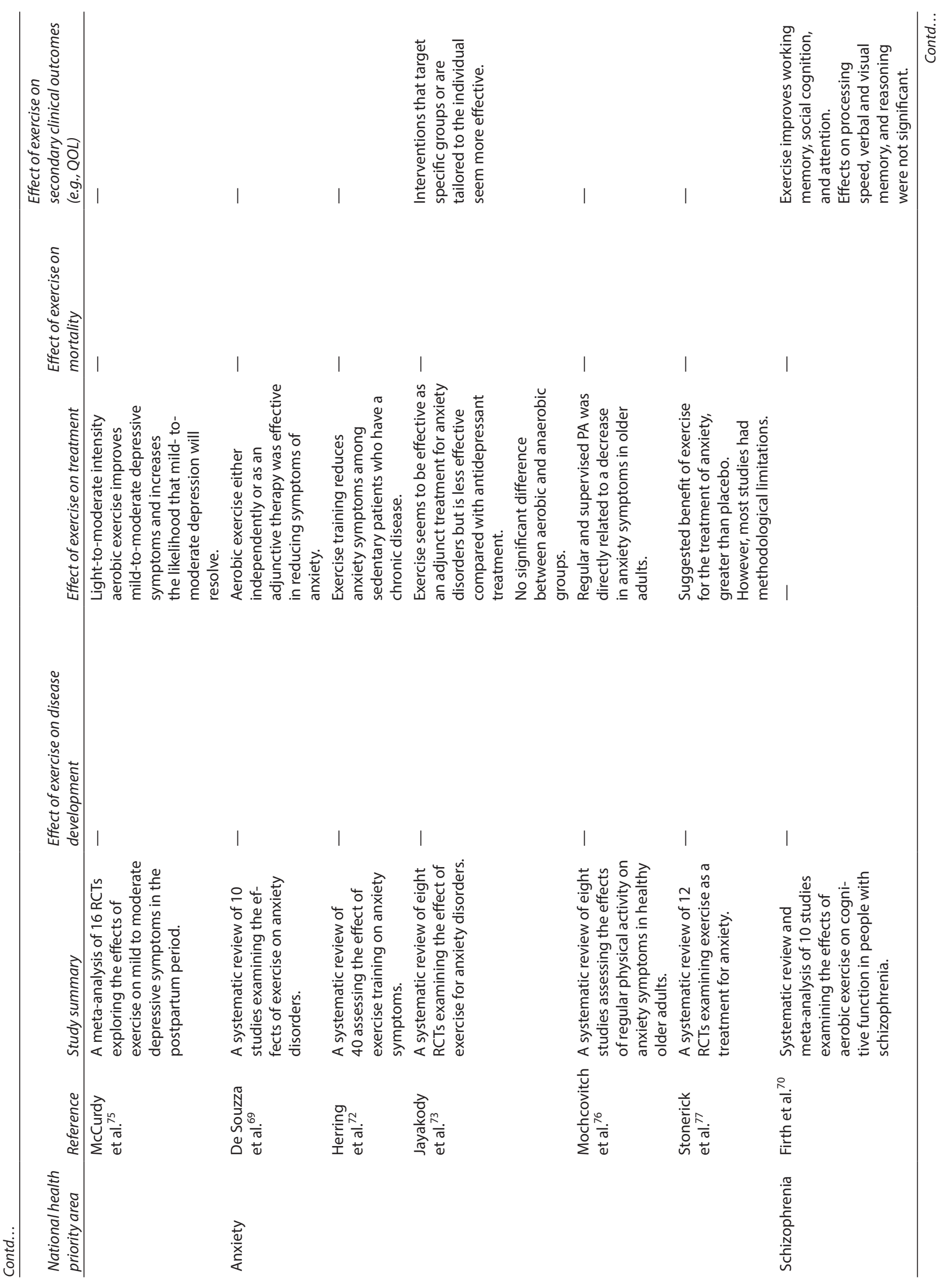




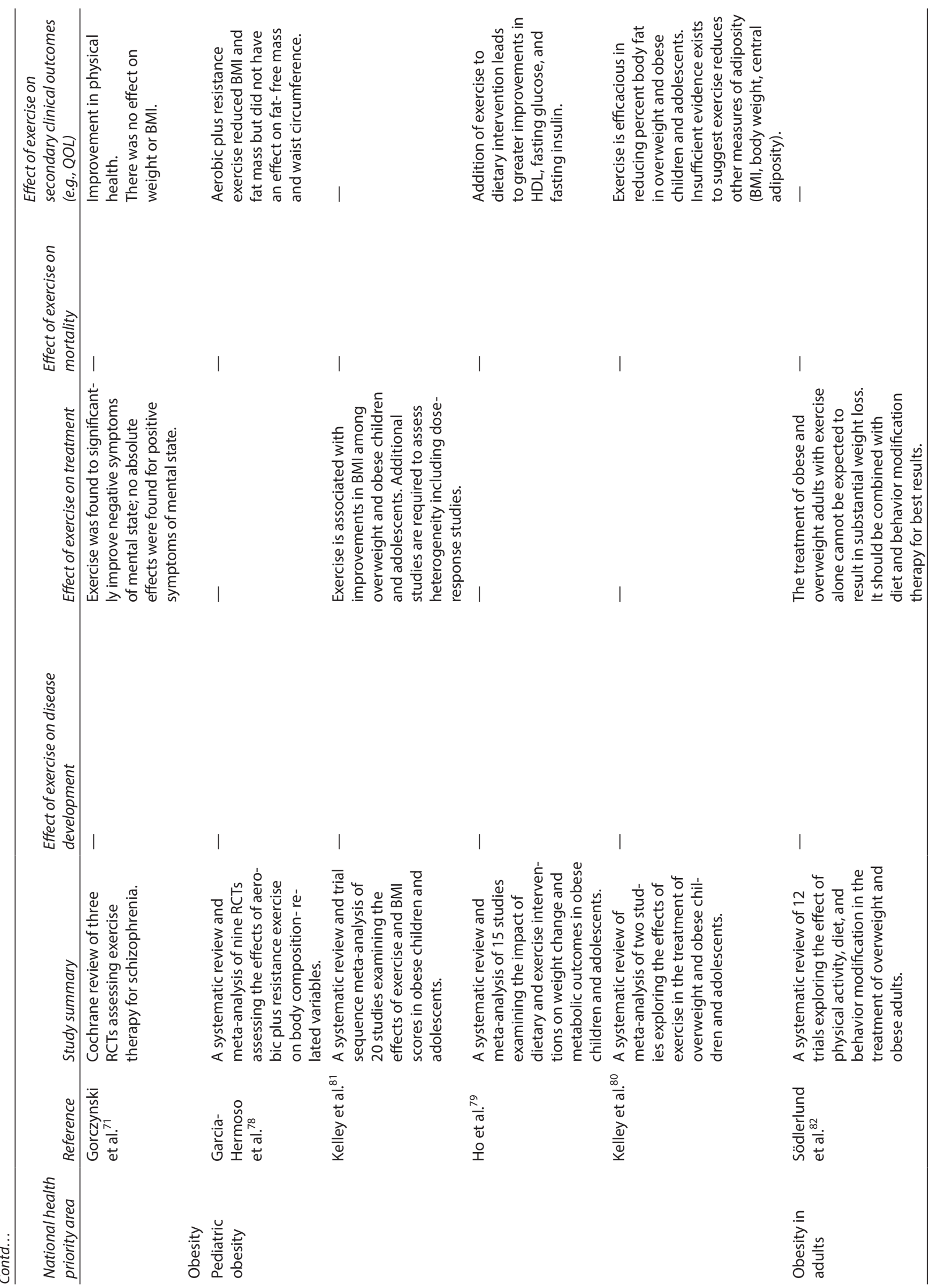


Appendix D: Methodological quality ratings of reviewed papers and interrelated agreement

Assessing the methodological quality of systematic reviews (AMSTAR)

\begin{tabular}{|c|c|c|c|c|c|c|c|c|c|c|c|c|c|}
\hline \multirow[b]{2}{*}{ Reference } & \multicolumn{13}{|c|}{ Assessing the methodological quality of systematic reviews (AMSTAR) } \\
\hline & 1 & 2 & 3 & 4 & 5 & 6 & 7 & 8 & 9 & 10 & 11 & Total & Percentage \\
\hline Bartels et al. ${ }^{10}$ & 1 & 1 & 1 & 0 & 1 & 1 & 1 & 1 & 1 & 1 & 0 & 9 & 81.8 \\
\hline Fransen et al. ${ }^{13}$ & 1 & 1 & 1 & 0 & 1 & 1 & 1 & 1 & 1 & 1 & 0 & 9 & 81.8 \\
\hline Fransen et al. ${ }^{14}$ & 1 & 1 & 1 & 0 & 1 & 1 & 1 & 1 & 1 & 1 & 0 & 9 & 90.9 \\
\hline Waller et al. ${ }^{19}$ & 0 & 1 & 1 & 0 & 0 & 1 & 1 & 1 & 1 & 0 & 0 & 6 & 63.6 \\
\hline Baillet et al. ${ }^{9}$ & 0 & 1 & 1 & 0 & 0 & 1 & 1 & 1 & 1 & 1 & 0 & 7 & 45.5 \\
\hline Cairns et al. ${ }^{11}$ & 0 & 0 & 1 & 0 & 1 & 1 & 1 & 1 & 0 & 0 & 0 & 5 & 81.8 \\
\hline Hurkmans et al. ${ }^{16}$ & 1 & 1 & 1 & 1 & 1 & 1 & 1 & 1 & 1 & 1 & 0 & 10 & 63.6 \\
\hline Choi et al. ${ }^{12}$ & 1 & 1 & 1 & 0 & 1 & 1 & 1 & 1 & 1 & 1 & 0 & 9 & 81.8 \\
\hline Oesch et al. ${ }^{18}$ & 0 & 1 & 1 & 0 & 0 & 1 & 1 & 1 & 1 & 1 & 0 & 7 & 70.8 \\
\hline Nikander et al. ${ }^{17}$ & 0 & 1 & 1 & 1 & 0 & 1 & 1 & 1 & 0 & 0 & 1 & 7 & 54.5 \\
\hline Howe et al. ${ }^{15}$ & 1 & 1 & 1 & 0 & 1 & 1 & 1 & 1 & 1 & 1 & 0 & 9 & 63.3 \\
\hline Beggs at al. ${ }^{20}$ & 1 & 1 & 1 & 1 & 1 & 1 & 1 & 1 & 1 & 1 & 0 & 10 & 90.9 \\
\hline Carson et al. ${ }^{21}$ & 1 & 1 & 1 & 1 & 1 & 1 & 1 & 1 & 1 & 1 & 0 & 10 & 90.9 \\
\hline Grande et al. ${ }^{24}$ & 1 & 1 & 1 & 1 & 1 & 1 & 1 & 1 & 1 & 1 & 0 & 10 & 90.0 \\
\hline Wanrooji et al. ${ }^{25}$ & 0 & 1 & 1 & 0 & 1 & 1 & 1 & 1 & 1 & 0 & 0 & 6 & 54.4 \\
\hline Eichenberger et al. ${ }^{23}$ & 0 & 1 & 1 & 0 & 0 & 0 & 1 & 1 & 1 & 1 & 1 & 7 & 63.6 \\
\hline Crosbie $^{22}$ & 0 & 0 & 1 & 0 & 0 & 1 & 1 & 1 & 1 & 0 & 1 & 6 & 54.5 \\
\hline Baumann et al. ${ }^{26}$ & 0 & 1 & 1 & 0 & 0 & 1 & 1 & 1 & 1 & 0 & 1 & 7 & 45.5 \\
\hline Bourke et al. ${ }^{28}$ & 0 & 1 & 1 & 1 & 0 & 0 & 1 & 1 & 1 & 1 & 1 & 8 & 45.5 \\
\hline Keogh et al. ${ }^{35}$ & 0 & 0 & 1 & 0 & 0 & 0 & 1 & 1 & 1 & 0 & 1 & 5 & 63.3 \\
\hline Bicego et al. ${ }^{27}$ & 0 & 0 & 1 & 0 & 0 & 1 & 1 & 1 & 1 & 0 & 0 & 5 & 90.9 \\
\hline Monninkhof et al. ${ }^{37}$ & 0 & 1 & 1 & 0 & 0 & 1 & 1 & 1 & 1 & 1 & 0 & 7 & 90.9 \\
\hline Furmaniak et al. ${ }^{32}$ & 1 & 1 & 1 & 1 & 1 & 1 & 1 & 1 & 1 & 1 & 0 & 10 & 90.9 \\
\hline Buffart et al. ${ }^{29}$ & 1 & 1 & 1 & 1 & 0 & 1 & 1 & 1 & 1 & 1 & 1 & 10 & 90.9 \\
\hline Cramp et al. ${ }^{31}$ & 1 & 1 & 1 & 1 & 1 & 1 & 1 & 1 & 1 & 1 & 0 & 10 & 54.5 \\
\hline Gerritsen et al. ${ }^{33}$ & 0 & 0 & 1 & 0 & 0 & 1 & 1 & 1 & 1 & 0 & 1 & 6 & 63.6 \\
\hline Mishra et al. ${ }^{36}$ & 1 & 1 & 1 & 1 & 1 & 1 & 1 & 1 & 1 & 1 & 0 & 10 & 63.6 \\
\hline Winzer et al. ${ }^{38}$ & 0 & 1 & 1 & 0 & 0 & 1 & 1 & 1 & 1 & 0 & 1 & 7 & 63.6 \\
\hline Cramer et al. ${ }^{30}$ & 0 & 1 & 1 & 0 & 0 & 1 & 1 & 1 & 1 & 1 & 0 & 7 & 63.6 \\
\hline Granger et al. ${ }^{34}$ & 0 & 1 & 1 & 0 & 0 & 1 & 1 & 1 & 1 & 0 & 1 & 7 & 81.8 \\
\hline Adsett et al. ${ }^{39}$ & 0 & 1 & 1 & 0 & 0 & 1 & 1 & 1 & 1 & 0 & 1 & 7 & 81.8 \\
\hline Lewinter et al. ${ }^{42}$ & 0 & 0 & 1 & 0 & 0 & 1 & 1 & 1 & 1 & 0 & 1 & 6 & 81.8 \\
\hline Taylor et al. ${ }^{45}$ & 1 & 1 & 1 & 0 & 1 & 1 & 1 & 1 & 1 & 1 & 0 & 9 & 81.8 \\
\hline Davies et al. ${ }^{41}$ & 1 & 1 & 1 & 0 & 0 & 1 & 1 & 1 & 1 & 1 & 0 & 9 & 90.9 \\
\hline Anderson et al. ${ }^{40}$ & 1 & 1 & 1 & 0 & 1 & 1 & 1 & 1 & 1 & 1 & 0 & 9 & 81.8 \\
\hline Risom et al. ${ }^{43}$ & 1 & 1 & 1 & 0 & 1 & 1 & 1 & 1 & 1 & 1 & 0 & 9 & 63.6 \\
\hline Saunders et al. ${ }^{44}$ & 1 & 1 & 1 & 1 & 1 & 1 & 1 & 1 & 1 & 1 & 0 & 10 & 72.7 \\
\hline Aarsland et al. ${ }^{46}$ & 0 & 1 & 0 & 0 & 0 & 1 & 1 & 1 & 1 & 1 & 1 & 7 & 63.6 \\
\hline Barreto et al. ${ }^{47}$ & 0 & 1 & 1 & 0 & 0 & 0 & 1 & 1 & 1 & 1 & 1 & 7 & 63.6 \\
\hline Forbes et al. ${ }^{48}$ & 1 & 1 & 1 & 1 & 1 & 1 & 1 & 1 & 1 & 1 & 0 & 10 & 90.9 \\
\hline Groot et al. ${ }^{49}$ & 1 & 1 & 1 & 0 & 1 & 1 & 1 & 1 & 1 & 1 & 0 & 9 & 81.8 \\
\hline Laver et al. ${ }^{50}$ & 1 & 1 & 1 & 1 & 0 & 1 & 1 & 1 & 1 & 0 & 1 & 9 & 81.8 \\
\hline Law et al. ${ }^{51}$ & 0 & 1 & 1 & 0 & 0 & 1 & 1 & 1 & 0 & 1 & 1 & 7 & 63.6 \\
\hline Littbrand et al. $^{52}$ & 0 & 1 & 1 & 0 & 1 & 1 & 1 & 1 & 0 & 1 & 0 & 7 & 45.5 \\
\hline Ohman et al. ${ }^{53}$ & 0 & 1 & 1 & 0 & 0 & 0 & 1 & 1 & 1 & 0 & 0 & 5 & 35.4 \\
\hline Pitkala et al. ${ }^{54}$ & 0 & 0 & 1 & 0 & 0 & 1 & 1 & 1 & 0 & 0 & 0 & 4 & 90.9 \\
\hline Young et al. ${ }^{55}$ & 1 & 1 & 1 & 1 & 1 & 1 & 1 & 1 & 1 & 1 & 0 & 10 & 63.6 \\
\hline Aguiar et al. ${ }^{56}$ & 1 & 0 & 1 & 0 & 0 & 1 & 1 & 1 & 1 & 1 & 1 & 8 & 72.7 \\
\hline Aune et al. ${ }^{57}$ & 0 & 0 & 1 & 0 & 1 & 0 & 1 & 1 & 1 & 1 & 1 & 7 & 81.8 \\
\hline Orozco et al..$^{60}$ & 1 & 1 & 1 & 0 & 1 & 1 & 1 & 1 & 1 & 1 & 0 & 9 & 72.7 \\
\hline
\end{tabular}


Contd...

\begin{tabular}{|c|c|c|c|c|c|c|c|c|c|c|c|c|c|}
\hline \multirow[b]{2}{*}{ Reference } & \multicolumn{13}{|c|}{ Assessing the methodological quality of systematic reviews (AMSTAR) } \\
\hline & 1 & 2 & 3 & 4 & 5 & 6 & 7 & 8 & 9 & 10 & 11 & Total & Percentage \\
\hline Bain et al. ${ }^{58}$ & 1 & 1 & 1 & 1 & 1 & 1 & 1 & 1 & 1 & 1 & 0 & 10 & 81.8 \\
\hline Han et al. ${ }^{59}$ & 1 & 1 & 1 & 0 & 1 & 1 & 1 & 1 & 1 & 1 & 0 & 9 & 45.5 \\
\hline Arnold et al. ${ }^{61}$ & 0 & 1 & 1 & 0 & 0 & 1 & 1 & 1 & 0 & 0 & 0 & 5 & 90.9 \\
\hline El-Khoury et al. ${ }^{62}$ & 0 & 1 & 1 & 0 & 0 & 1 & 1 & 1 & 1 & 1 & 1 & 8 & 72.7 \\
\hline Kendrick et al. ${ }^{63}$ & 1 & 1 & 1 & 1 & 1 & 1 & 1 & 1 & 1 & 1 & 0 & 10 & 63.6 \\
\hline Sherrington et al. ${ }^{66}$ & 0 & 1 & 1 & 0 & 0 & 1 & 1 & 1 & 1 & 1 & 1 & 8 & 72.7 \\
\hline Rossler et al. ${ }^{65}$ & 0 & 1 & 1 & 0 & 0 & 1 & 1 & 1 & 1 & 1 & 0 & 7 & 54.5 \\
\hline Lauersen et al. ${ }^{64}$ & 0 & 1 & 1 & 0 & 0 & 1 & 1 & 1 & 1 & 0 & 1 & 7 & 90.9 \\
\hline Cooney et al. ${ }^{67}$ & 1 & 1 & 1 & 1 & 1 & 1 & 1 & 1 & 1 & 1 & 0 & 10 & 81.8 \\
\hline Josefsson et al. ${ }^{74}$ & 0 & 0 & 1 & 1 & 0 & 1 & 1 & 1 & 1 & 0 & 0 & 6 & 72.7 \\
\hline Daley et al. ${ }^{68}$ & 0 & 1 & 1 & 1 & 0 & 1 & 1 & 1 & 1 & 1 & 1 & 9 & 63.6 \\
\hline McCurdy et al. ${ }^{75}$ & 0 & 1 & 1 & 1 & 0 & 1 & 1 & 1 & 1 & 0 & 1 & 8 & 72.7 \\
\hline De Souzza et al. ${ }^{69}$ & 0 & 1 & 1 & 0 & 0 & 1 & 1 & 1 & 0 & 1 & 1 & 7 & 72.7 \\
\hline Herring et al. $^{72}$ & 0 & 1 & 1 & 0 & 0 & 0 & 1 & 1 & 1 & 1 & 1 & 7 & 54.5 \\
\hline Jayakody et al. ${ }^{73}$ & 0 & 1 & 1 & 0 & 0 & 1 & 1 & 1 & 1 & 1 & 1 & 8 & 54.5 \\
\hline Mochcovitch et al. ${ }^{76}$ & 0 & 0 & 1 & 0 & 0 & 0 & 1 & 1 & 1 & 1 & 1 & 6 & 81.8 \\
\hline Stonerick et al. ${ }^{77}$ & 0 & 1 & 1 & 0 & 0 & 0 & 1 & 1 & 0 & 1 & 1 & 6 & 63.6 \\
\hline Firth et al. ${ }^{70}$ & 0 & 1 & 1 & 0 & 0 & 1 & 1 & 1 & 1 & 1 & 1 & 8 & 63.6 \\
\hline Gorczynski et al. ${ }^{71}$ & 1 & 1 & 1 & 0 & 1 & 1 & 1 & 1 & 1 & 1 & 0 & 9 & 72.7 \\
\hline Garcia-Hermoso et al. ${ }^{78}$ & 0 & 1 & 1 & 0 & 0 & 1 & 1 & 1 & 1 & 1 & 1 & 8 & 81.8 \\
\hline Kelley et al. ${ }^{81}$ & 1 & 1 & 1 & 0 & 0 & 1 & 1 & 1 & 1 & 1 & 1 & 9 & 63.6 \\
\hline Ho et al. ${ }^{79}$ & 0 & 1 & 1 & 0 & 0 & 1 & 1 & 1 & 1 & 1 & 0 & 7 & 81.8 \\
\hline Kelley et al..$^{80}$ & 1 & 1 & 1 & 0 & 1 & 1 & 1 & 1 & 0 & 1 & 1 & 9 & 36.4 \\
\hline Södlerlund et al. ${ }^{82}$ & 0 & 0 & 1 & 0 & 0 & 1 & 1 & 1 & 0 & 0 & 0 & 4 & 54.5 \\
\hline
\end{tabular}

